\title{
Clinical efficacy and increased donor strain engraftment after antibiotic pretreatment in a randomized trial of ulcerative colitis patients receiving fecal microbiota transplant
}

Byron J. Smith A,B (ORCID: 0000-0002-0182-404X)

Yvette Piceno ${ }^{C}$ (ORCID: 0000-0002-7915-4699)

Martin Zydek ${ }^{\mathrm{D}}$

Bing Zhang D (ORCID: 0000-0002-3377-0963)

Lara Aboud Syriani $\mathrm{E}$

Jonathan $\mathrm{P}$. Terdiman ${ }^{\mathrm{D}}$

Zain Kassam ${ }^{F}$

Averil Ma G (ORCID: 0000-0003-4817-1258)

Susan V. Lynch ${ }^{\mathrm{D}, \mathrm{H}}$ (ORCID: 0000-0001-5695-7336)

Katherine S. Pollard A,B,I,* (ORCID: 0000-0002-9870-6196)

Najwa El-Nachef ${ }^{D, *}$

A The Gladstone Institute of Datascience and Biotechnology, San Francisco, CA

B Department of Epidemiology and Biostatistics, University of California, San Francisco, CA

C Symbiome, Inc., San Francisco, CA

D Division of Gastroenterology, University of California, San Francisco, CA

E College of Osteopathic Medicine of the Pacific, Western University of Health Sciences, Pomona, CA

F Finch Therapeutics, Somerville, MA

G Department of Medicine, University of California, San Francisco, CA

${ }^{H}$ Benioff Center for Microbiome Medicine, University of California, San Francisco, CA

' Chan-Zuckerberg Biohub, San Francisco, CA

${ }^{*}$ Corresponding authors:

katherine.pollard@gladstone.ucsf.edu

najwa.elnachef@ucsf.edu 
medRxiv preprint doi: https://doi.org/10.1101/2021.08.07.21261556; this version posted August 10, 2021. The copyright holder for this preprint (which was not certified by peer review) is the author/funder, who has granted medRxiv a license to display the preprint in perpetuity.

It is made available under a CC-BY 4.0 International license.

\begin{abstract}
Fecal microbiota transplant is a promising therapy for ulcerative colitis. Parameters maximizing effectiveness and tolerability are not yet clear, and it is not known to what degree the transmission of donor microbes to patients is important. Here (clinicaltrails.gov: NCT03006809) we have tested the effects of antibiotic pretreatment (neomycin, vancomycin, and metronidazole, $500 \mathrm{mg}$ twice a day for 5 days) and compared two modes of maintenance dose delivery, capsules versus enema, in a randomized, pilot, open-label, $2 \times 2$ factorial design with 22 patients analyzed (30 patients randomized) with mild to moderate UC (total Mayo score 4-9). Clinically, the treatment was well-tolerated with favorable safety profile. Patients receiving antibiotic pretreatment trended toward greater remission after six weeks of treatment (55\% vs. $18 \%, p=0.18$ ), and no significant differences were found between maintenance dosing via capsules versus enema. In exploratory analyses, microbiome turnover at both the species and strain levels was extensive and significantly more pronounced in the pretreated patients. Associations were also revealed between taxonomic turnover and changes in the composition of primary and secondary bile acids. Together these findings suggest that antibiotic pretreatment contributes to microbiome engraftment and possibly clinical effectiveness, and validate longitudinal strain tracking as a powerful way to monitor the dynamics and impact of microbiota transfer.
\end{abstract}

\title{
Introduction
}

Fecal microbiota transplant (FMT) is recognized as a promising therapy for inflammatory bowel disease, in particular ulcerative colitis (UC) $(1,2)$. According to meta-analyses, half of the UC patients receiving FMT display a response to treatment, and one third achieve clinical remission of their symptoms. (3-6) after FMT. Across four randomized, placebo-controlled studies (RCTs) (7-10), $28 \%$ of FMT and only $9 \%$ of placebo recipients achieved remission (4). Despite this potential, the mechanism by which FMT improves gut health is not known, which hinders attempts to increase its efficacy. In addition, the role of the gut microbiome in the etiology of UC is unsettled; the composition of the gut microbiome is known to differ in UC cases compared to healthy controls but it remains unclear if these differences are a major cause of the disease or a result of underlying inflammation $(11,12)$. Understanding how FMT facilitates remission may shed light on the underlying biology of UC and potentially enable the development of novel therapies.

Parameters maximizing the efficacy of FMT for UC have not yet been established, and extensive study-to-study variation in treatment protocols has made comparisons challenging. Many studies use antibiotic pretreatment to diminish the patients' own baseline microbiomes before FMT (e.g. 13, 14), and a recent meta-analysis has found higher efficacy in studies using this approach (6), but none of the four published RCTs used antibiotics in this way (7-10).

Protocols also vary greatly in the number and method of FMT application. Most include an initial dose via colonoscopy, and many follow up with a maintenance dose regimen ranging from just once three weeks after the initial dose ( 7 ) to five times a week for two months (9). Maintenance doses may improve efficacy (6), but their cost and tolerability are substantial challenges. The recent development of FMT capsule formulations may make maintenance dosing logistically easier and more acceptable to patients (15-17). However, it is unclear if FMT capsules, administered orally, are as effective as other delivery modes for transferring the donor's microbiotia. Digestive enzymes, pH fluctuations, bile salts, and other environmental stresses may affect which taxa survive transit through the small bowel. Conversely, donor material may reach the upper colon more effectively when applied by capsule than by enema. While capsules 
medRxiv preprint doi: https://doi.org/10.1101/2021.08.07.21261556; this version posted August 10, 2021. The copyright holder for this preprint (which was not certified by peer review) is the author/funder, who has granted medRxiv a license to display the preprint in perpetuity.

It is made available under a CC-BY 4.0 International license.

have been shown to be no less effective for the treatment of recurrent Clostridioides difficile infections $(15,18)$, it is not yet clear whether they have equivalent efficacy for UC.

Many optimizations of FMT for UC-antibiotic pretreatment, repeated maintenance doses, anaerobic preparation, etc.-assume that effectiveness depends on the sustained transfer of microbial taxa and their functional capacities (19), although this has not been confirmed.

Likewise, it is not clear whether a subset of donor communities might be particularly effective. In fact, features of the microbiome, in either patients or their donors, that predict FMT efficacy have not been convincingly identified (19-21). An important challenge for understanding the role of engraftment is in distinguishing taxa originating in donors' or recipients' microbiomes (22, 23). 16S rRNA gene surveys and most tools that operate on shotgun metagenomic libraries cannot differentiate between donor and patient populations of the same species, due to limited taxonomic resolution (24). The application of recently developed approaches to identifying and tracking populations at the level of strains rather than species would both increase the detection of transfer events and help elucidate the relationship between community turnover and recovery from UC.

Furthermore, recent work has attempted to identify a link between the metabolic function of the gut microbiota and UC (25). Numerous results indicate involvement of bile acids (BAs) in IBD and recovery, in particular their transformation to secondary BAs by microbes (26-34). Paired BA metabolomics with metagenomic sequencing before, during, and after FMT might help to elucidate the importance of these signalling compounds in UC treatment $(1,25)$.

Here we experimentally test the impacts of both antibiotic pretreatment and maintenance dosing protocols on the microbiome and the efficacy of FMT therapy in patients with mild to moderate UC. Along with clinical features, we analyze a longitudinal, multimodal dataset describing the taxonomic and functional gene composition of the microbiota, as well as primary and secondary BAs in stool. Our data comprise a novel resource pairing strain-level taxonomic resolution and BA profiles over a sustained FMT protocol. We find that antibiotic pretreatment substantially increases the transfer of host bacteria to patients and is weakly associated with greater FMT efficacy. Notably, rates of engraftment and clinical remission were similar with both capsules and enemas as maintenance dosing methods. Our results will contribute to optimized protocols for the transfer of donor microbes to patients, as well as improved understanding of the role of the gut microbiome in UC.

\section{Results}

\section{Study design and patient demographics}

We conducted a prospective trial of FMT in patients with active, mild to moderate UC (illustrated in Fig. 1A). Patients were randomized into arms receiving antibiotic pretreatment $(A B X+)$ or not (ABX-), and maintenance doses via either enema (ENMA) or capsules (CAPS). Detailed demographics across arms are available in Supplementary Table 1. For both the initial FMT and maintenance doses, each participant received screened, prepared stool from just one of four healthy donors. Two colonoscopies were performed to assess disease severity and location, one concurrent with the initial FMT application (D0), and the second two weeks after the last maintenance dose (F1).

Patients sampled their own stools before the initiation of therapy (baseline sample, B), after the end of antibiotic pretreatment, before each of the six maintenance doses (D1-6), and before each of the three follow-up appointments (F1-3). Maintenance doses were administered weekly, 
medRxiv preprint doi: https://doi.org/10.1101/2021.08.07.21261556; this version posted August 10, 2021. The copyright holder for this preprint (which was not certified by peer review) is the author/funder, who has granted medRxiv a license to display the preprint in perpetuity.

It is made available under a CC-BY 4.0 International license.

and follow-up appointments scheduled approximately 2 weeks, 6 weeks, and 14 weeks after the last maintenance dose.

Patients were interviewed for the occurrence of solicited adverse events during each study visit and up to 12 months after completion of the study. Minor events included self-limited abdominal pain, constipation, diarrhea, vomiting, abdominal discomfort, excessive flatulence and fever. Notably, of the three occurrences of vomiting in the CAPS arms, all were linked to the same donor (D0485) and happened within a few hours after administration of capsules. No aspiration events occurred. Five patients experienced worsening UC during the study period. Two withdrew due to a need for escalation of therapy. One UC flare constituted a serious adverse event as it required hospitalization but clinicians identified the withdrawal of steroids as a more likely cause then the study treatment. Adverse events are detailed in Supplementary Table 2.

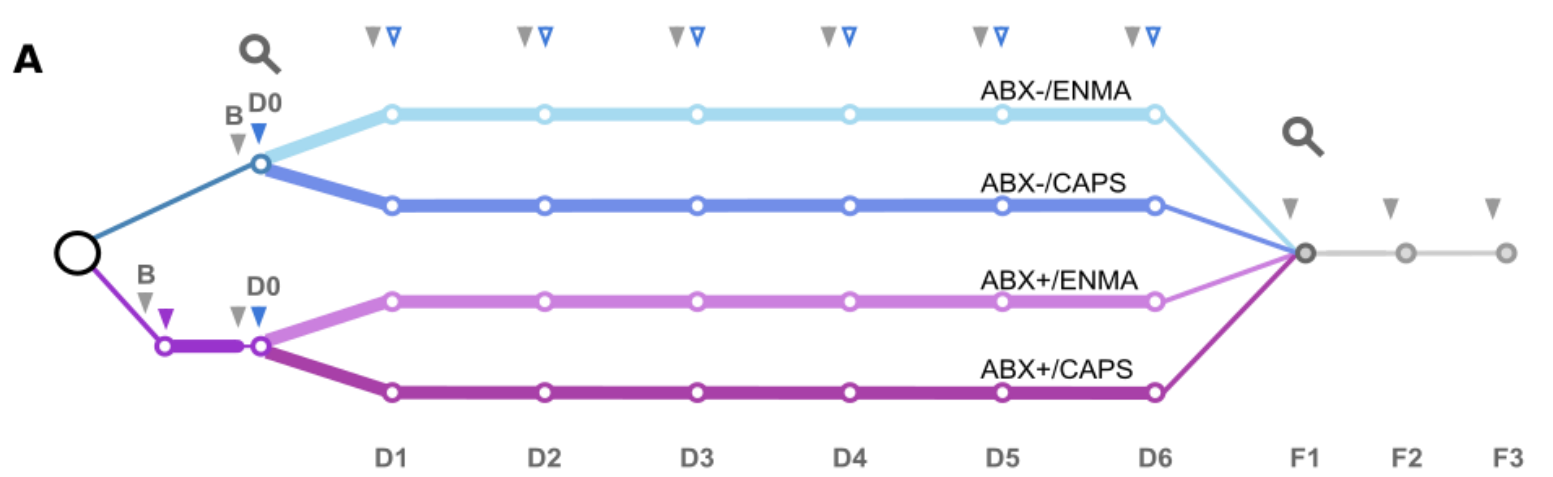

$\nabla$ stool collection $\quad \nabla$ initiation of antibiotic pre-treatment $\quad \nabla \nabla$ initial/maintenance doses $\mathbf{Q}$ colonoscopy

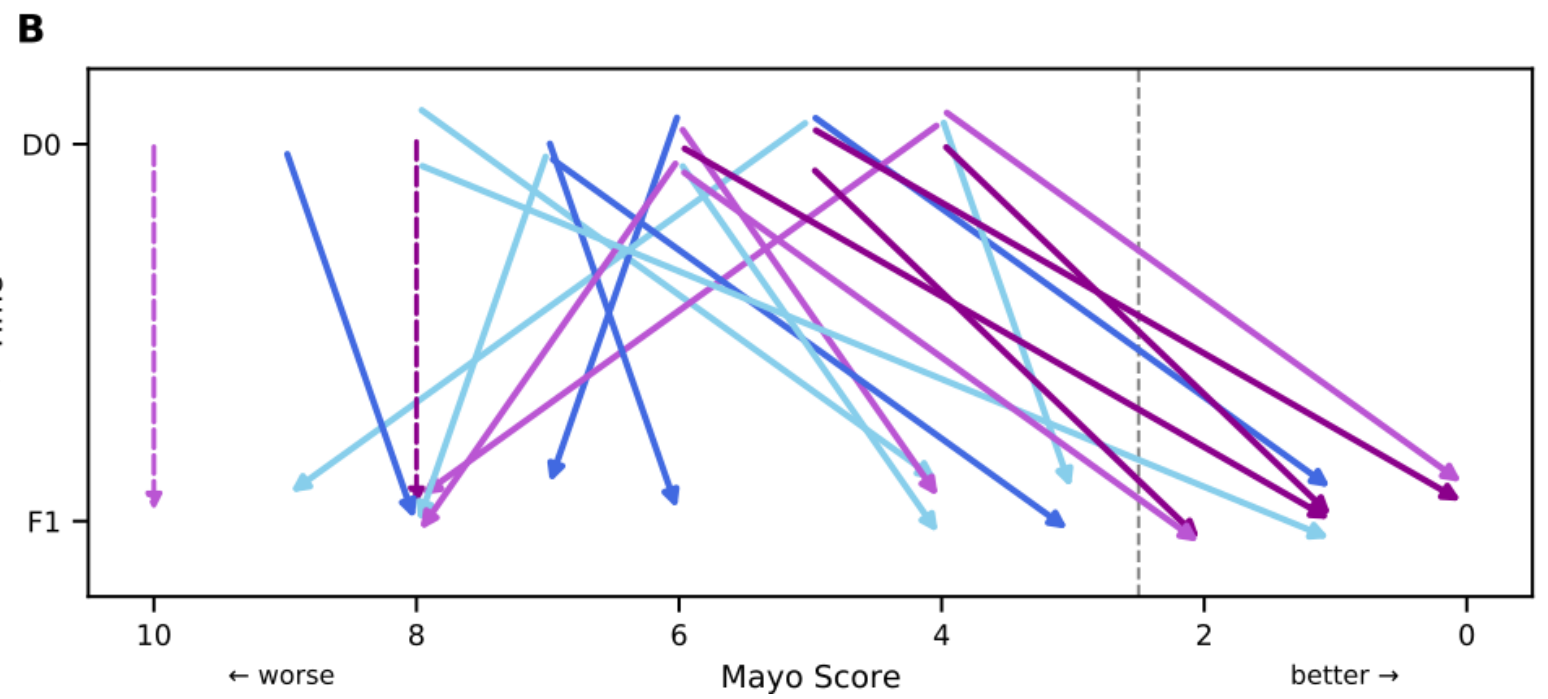

Figure 1: Study design and primary efficacy endpoint of an experimental FMT treatment for UC, showing improved symptoms at follow-up, particularly among patients receiving antibiotics. In our $2 \times 2$ factorial design, each patient either received antibiotic pretreatment $\left(A B X_{+}\right)$or not $(A B X-)$, and either received capsules (CAPS) or enama (ENMA) for maintenance dosing. (A) Major events during the longitudinal study, including baseline $(B)$ and subsequent fecal sample collections (grey arrowheads), colonoscopies (magnifying glasses), initial FMT (D0, solid blue arrowhead), six weekly maintenance doses (D1-D6, open blue arrowheads), and three follow-up appointments (F1-F3). The start of oral antibiotics is represented 
medRxiv preprint doi: https://doi.org/10.1101/2021.08.07.21261556; this version posted August 10, 2021. The copyright holder for this preprint (which was not certified by peer review) is the author/funder, who has granted medRxiv a license to display the preprint in perpetuity.

It is made available under a CC-BY 4.0 International license.

(purple arrowhead). (B) Change in Mayo scores of each patient between D0 (top) and F1 (bottom). Dashed arrows show the DO Mayo score of patients who withdrew from the study due to worsening symptoms. Patient arrows are colored by arm and shifted vertically by a small, arbitrary amount to increase visual distinction. The grey dotted line just left of Mayo score 2 marks the remission threshold. All patients with a Mayo score $\leq 2$ at F1 also had an endoscopy sub-score that decreased by at least 1 point; therefore all were considered to be in remission.

\section{Antibiotic pretreatment may increase FMT efficacy}

We evaluated the clinical impact of treatment using the Mayo score, which compounds subscores including the severity of rectal bleeding, stool frequency, and an endoscopic assessment of epithelial inflammation (35). Clinical remission, defined as a total Mayo score $\leq 2$ at the first follow-up (time-point F1) and endoscopic improvement by $\geq 1$, was reached in a total of 8 patients out of the 20 who received a follow-up colonoscopy, consistent with past studies of FMT for UC (6). Of these, 6 of $9(67 \%) A B X+$ patients achieved remission, while only 2 of 11 $(18 \%)$ did in the ABX- arms ( $\mathrm{p}=0.065$ by two-sided Fisher exact test). While short of a traditional significance threshold, our results nonetheless suggest increased remission in patients receiving antibiotic pretreatment.

Two additional patients, both in ABX+ arms, dropped out of the study due to a flare of UC symptoms before $\mathrm{F} 1$. If these patients are included in statistical analyses, the $A B X+$ remission rate drops to $55 \%$ (6 of 11$)$, which is not significantly different from $A B X-(p=0.18)$. Tests of other treatment covariates-maintenance method and donor-showed no significant effects, and more complicated models (e.g. those involving multiple covariates and interactions) could not be fit given the small sample size and large number of covariates. Patients were classified as "responders", a less stringent designation than remission, if their total Mayo score decreased by 3 or more points. Ten of 22 patients were responders, with no statistical association with pretreatment, maintenance method, or donor, tested individually by logistic regression.

Overall, Mayo scores decreased from initial FMT (D0 time point) to first follow up ( $F 1 ; p=0.015$ by Wilcoxon signed-rank test, Fig. 1B). However, the magnitude of this change did not appear to be related to any of the treatment covariates. For instance, $A B X+$ patients did not experience a greater reduction in Mayo score than did ABX-patients, despite the trend towards a higher rate of remission reported above. Since two of four Mayo subscores-for stool frequency and rectal bleeding-were assessed at multiple time points, we analyzed the effect of treatment parameters on each of these during maintenance and follow-up under a repeated measures framework. We found no effect of antibiotics or maintenance methods on either sub-score. There was a significant donor effect on rectal bleeding ( $p<1 e-3$ by LRT in a General Estimating Equations framework), but not on stool frequency $(p=0.12)$. Larger studies may be necessary to detect subtle effects of treatment on Mayo scores.

\section{Metagenomics and metabolomics generate complementary representations of patients' microbiomes before, during, and after treatment}

In order to document the impacts of FMT on the gut microbiome, we longitudinally profiled the taxonomic composition and functional capacity of the fecal community in a subset of patients using several complementary methods. Surveys of the 16S rRNA taxonomic marker gene were paired with shotgun metagenomic sequencing to establish species-level, strain-level, and functional gene composition. In addition, primary and secondary BA profiles were collected via untargeted metabolomics. Details of which samples and profiles were collected for each patient are available in Supplementary Tables 3-6. 
medRxiv preprint doi: https://doi.org/10.1101/2021.08.07.21261556; this version posted August 10, 2021. The copyright holder for this preprint (which was not certified by peer review) is the author/funder, who has granted medRxiv a license to display the preprint in perpetuity.

It is made available under a CC-BY 4.0 International license.

Sequencing surveys of the 16S rRNA gene revealed 857 unique amplicon sequence variants (ASVs). In addition, shotgun metagenomic libraries metagenotyped with GT-PRO (36) identified 371 species. To increase the resolution of the taxonomic data, we leveraged single nucleotide polymorphisms (SNPs) as a means to distinguish strains within the broader species categories. Using Strain Finder (22), we identified 3846 strains with detectable abundance in at least two samples. The larger number of strains than ASVs or metagenomic species suggests that strainlevel resolution can better differentiate the taxa transferred from donors from those present in patients before FMT.

Functional gene composition was characterized by annotating shotgun metagenomic reads with KEGG gene families (KOs), which identified 7587 unique annotations. Metabolomics identified and quantified a total of 51 primary and secondary BAs across all samples, reflecting the remarkable chemical diversity of these molecules.

\section{Microbiome features cluster by both patient and donor after FMT}

To determine the extent to which FMT modified the patients' microbiomes, we examined the clustering of genomic and metabolic profiles by patient and by donor during and after FMT treatment (see Fig. 2).

Clustering by donor was detected for several of the profiles (Fig. 2A-E), demonstrating the impacts of FMT. Specifically, strain profiles clustered robustly by donor at every time point after the initial colonoscopy, while-unsurprisingly-baseline samples showed no such clustering. Species profiles, both metagenomic and ASV based, exhibited weaker but also significant clustering by donor during maintenance and follow-up time points. For functional gene annotations, donor clustering was significant, though far less dramatic. However, since this clustering was seen even with baseline samples (ANOSIM $R=0.24, p=0.038$ ), clustering at D1 $(R=0.25, p=0.048), D 3(R=0.21, p=0.072)$, and $D 5(R=0.34, p=0.017)$ might be spurious. The limited clustering of functional gene profiles by donor suggests that these are either highly similar across donors or less effectively transferred to patients.

BA profiles showed some signs of clustering by donor at the $F 1$ and $F 2$ time points $(R=0.18$, 0.22 , and $p=0.094,0.060$ respectively), raising the interesting possibility that FMT treatment could have a donor-dependent impact on patients' BA profiles. However, this is not a substantial or significant effect; given the small sample size, it is not clear that it reflects a reproducible result.

Despite the perturbation of FMT treatment, clustering by patient across time points was observed for all four microbiome profiles (Fig. 2F, Supplementary Fig. 5). This effect was strongest at the strain level $(R=0.90, p<0.001)$, followed by species level $(R=0.72, p<0.001)$. Intriguingly, both functional annotations $(R=0.32, p<0.001)$ and $B A$ profiles $(R=0.52, p<0.001)$ clustered significantly by patient, suggesting that FMT was unable to uniformly affect these aspects of patients' microbiomes, and therefore patient-specific effects may modulate the impacts of FMT. 
medRxiv preprint doi: https://doi.org/10.1101/2021.08.07.21261556; this version posted August 10, 2021. The copyright holder for this preprint (which was not certified by peer review) is the author/funder, who has granted medRxiv a license to display the preprint in perpetuity.

It is made available under a CC-BY 4.0 International license.

A

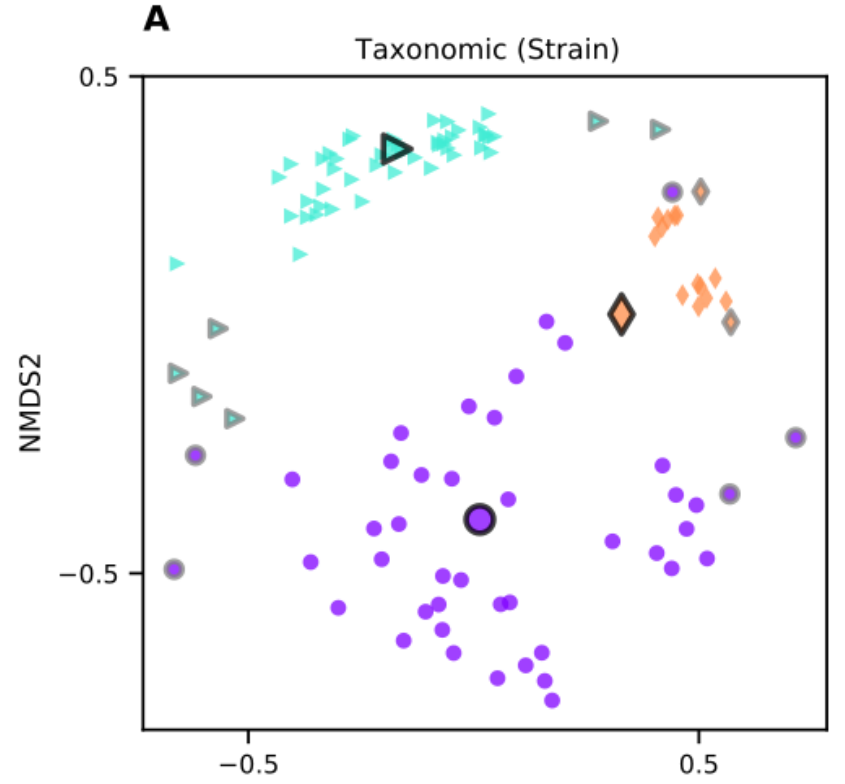

C
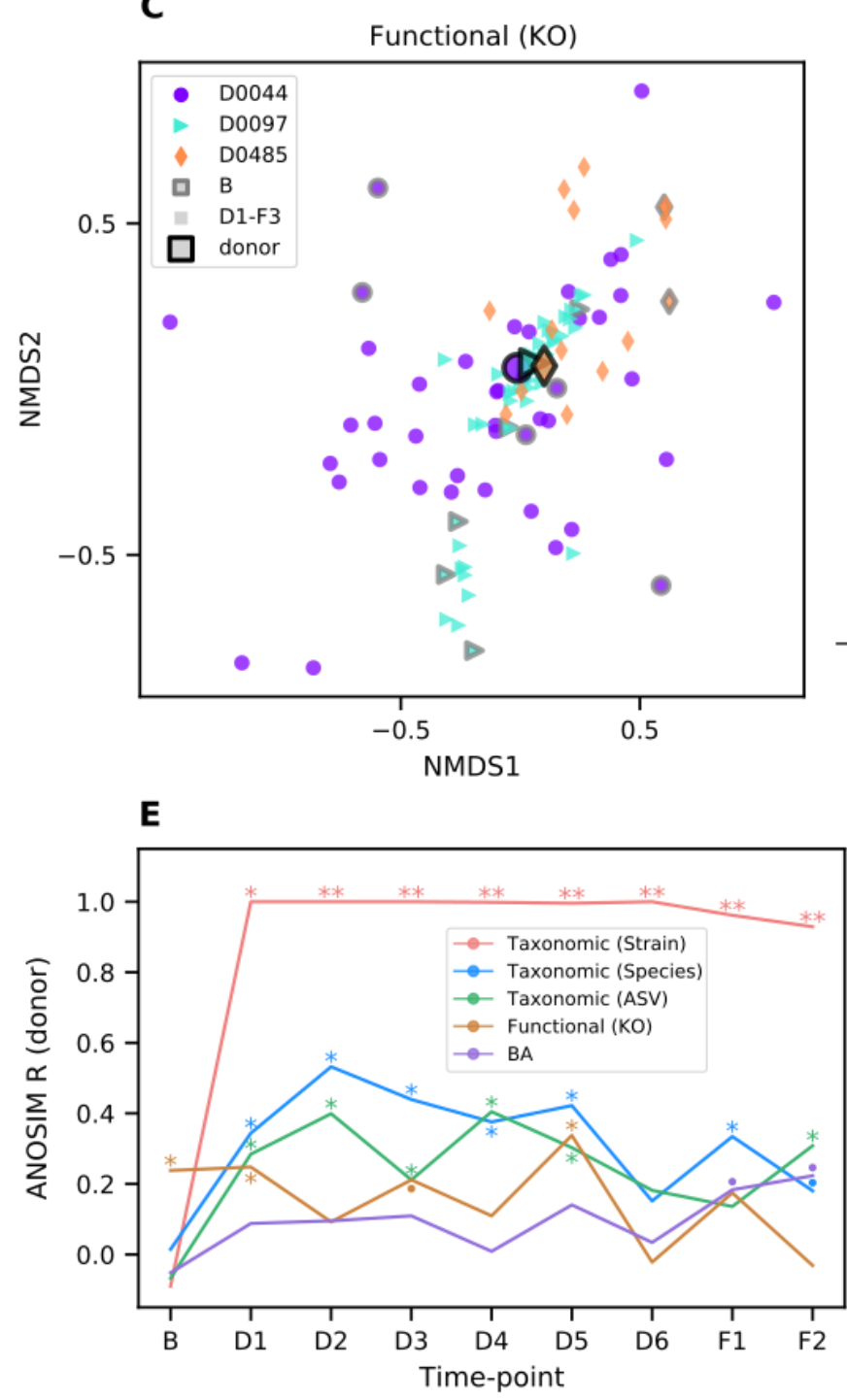

B
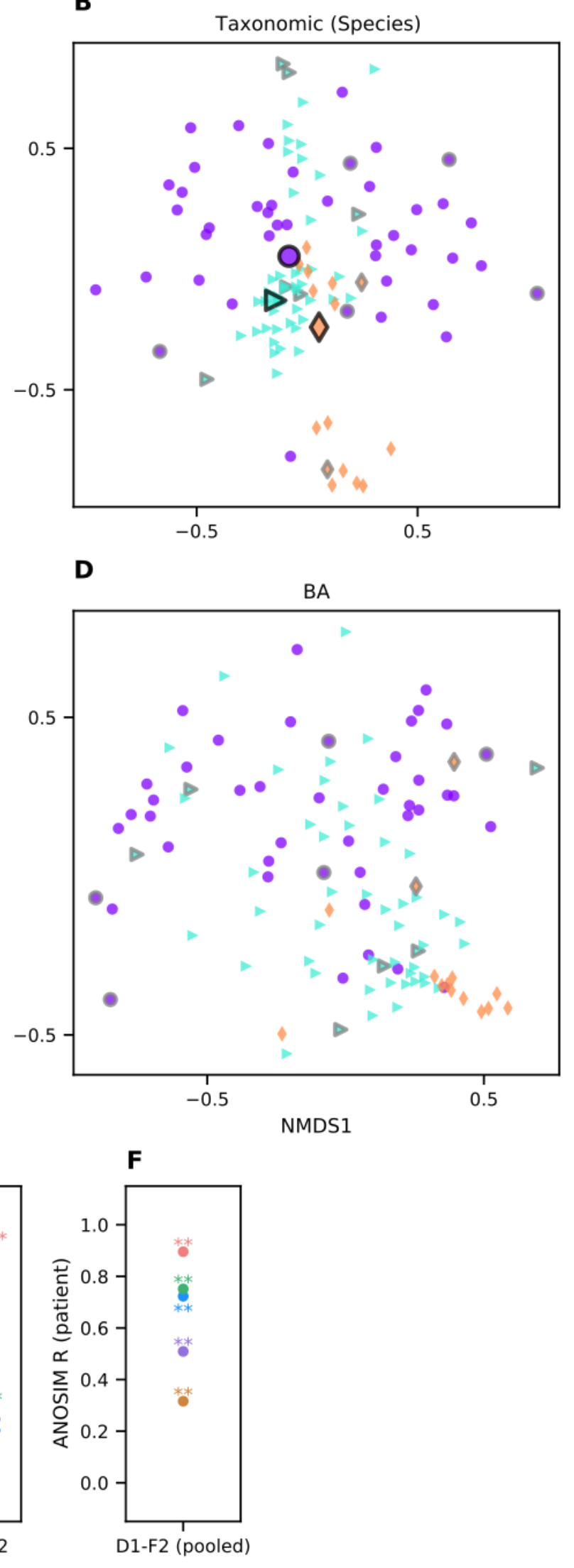
medRxiv preprint doi: https://doi.org/10.1101/2021.08.07.21261556; this version posted August 10, 2021. The copyright holder for this preprint (which was not certified by peer review) is the author/funder, who has granted medRxiv a license to display the preprint in perpetuity. It is made available under a CC-BY 4.0 International license.

Figure 2: Samples cluster within patient and donor groups during and after FMT treatment. (A-D) Nonmetric multidimensional scalings were calculated from pairwise sample comparisons based on $B C$ dissimilarity of taxonomic profiles from shotgun metagenomes at strain $(A)$, and species resolution (B), and on cosine dissimilarity of functional gene $(C)$ and $B A$ profiles $(D)$. The orientations and scales of axes are arbitrary, and proximity on a plot reflects similarity. Markers represent individual fecal samples from patients (no black outline) or the mean of all samples from a single donor (black outlines). Shapes and colors are matched between patients and their respective donors. Patients' baseline samples are outlined in grey. Identical ordinations colored by individual subjects are available in Supplementary Fig. 5. (E, F) ANOSIM $R$ scores, an index of clustering strength based on pairwise sample dissimilarities, for the four profiles from (A-D) as well as an additional taxonomic profile based on 16S rRNA gene ASVs. Larger $R$ values indicate stronger clustering by donor at each time point $(E)$ or by patient across pooled time points $(F)$. Significance, as assessed by ANOSIM permutation test $(n=9999): p \leq 0.1(\bullet), p \leq 0.05(*), p \leq 0.001\left(^{* *}\right)$.

\section{Taxonomic analysis reveals rapid and extensive transfer of donor species and strains to patients}

The clustering of taxonomic profiles by donor indicates effective colonization of patients during FMT. To quantify this transfer, we tracked bacteria species that were specific to patients, specific to their respective donor, or shared by both. Patients had a median of 77 donor species at $\mathrm{F} 1$ (representing a median $25 \%$ of their total community relative abundance) and $56(12.3 \%)$ at F2. The sensitivity of this approach is limited, however, by the preponderance of shared species, which make up most of the baseline community: median $56 \%$ of species and $73 \%$ of relative abundance in baseline samples. The fractions of shared taxa estimated from 16S rRNA gene amplicon surveys is nearly identical: $55 \%$ of ASVs comprising $71 \%$ of relative abundance.

By contrast, only a median of $24 \%$ of strains were shared at baseline. Using strains therefore creates more opportunities to infer transfer and engraftment and greatly improves the taxonomic resolution of our analyses (see Fig. 3). Overall, patients became more populated with donor strains over the course of the study (Fig. 3C). Patients had a median of 260 donor strains at F1 (57\% of relative abundance), and $232(50 \%)$ at F2, about six weeks after the end of treatment. The introduction of donor strains is concomitant with patient-specific strains dropping from $87 \%$ of total community abundance at baseline (the remaining $13 \%$ shared with their donor) to $12 \%$ and $20 \%$ of the community at F1 and F2, respectively (Fig. 3A). Patients' BC similarity (1 - BC dissimilarity) to donors based on strain profiles increased from a median of 0.01 at baseline to 0.17 at $F 1$ ( $p<0.001$ by MWU test, (Fig. 3B). Notably, patients' communities were more similar to their respective donor than to their original composition, with a BC similarity to their own baseline of 0.09 by F1 (Fig. 3D), indicating that FMT profoundly affects the taxonomic composition of patients' gut microbiomes.

Donor strains were already detected in patients' fecal community profiles at the D1 time point, prior to the first maintenance dose and just one week after the initial FMT (Fig. 3C). Interestingly, the relative abundance of donor strains, or the BC similarity to the donor community (Fig. 3D), did not substantially increase at subsequent time points ( $p>0.05$ for all comparisons of D1 to D2-F2 by Wilcoxon rank-sum test), suggesting that repeated maintenance doses may have only limited importance in ensuring strain transfer. 
medRxiv preprint doi: https://doi.org/10.1101/2021.08.07.21261556; this version posted August 10, 2021. The copyright holder for this preprint (which was not certified by peer review) is the author/funder, who has granted medRxiv a license to display the preprint in perpetuity.

It is made available under a CC-BY 4.0 International license.
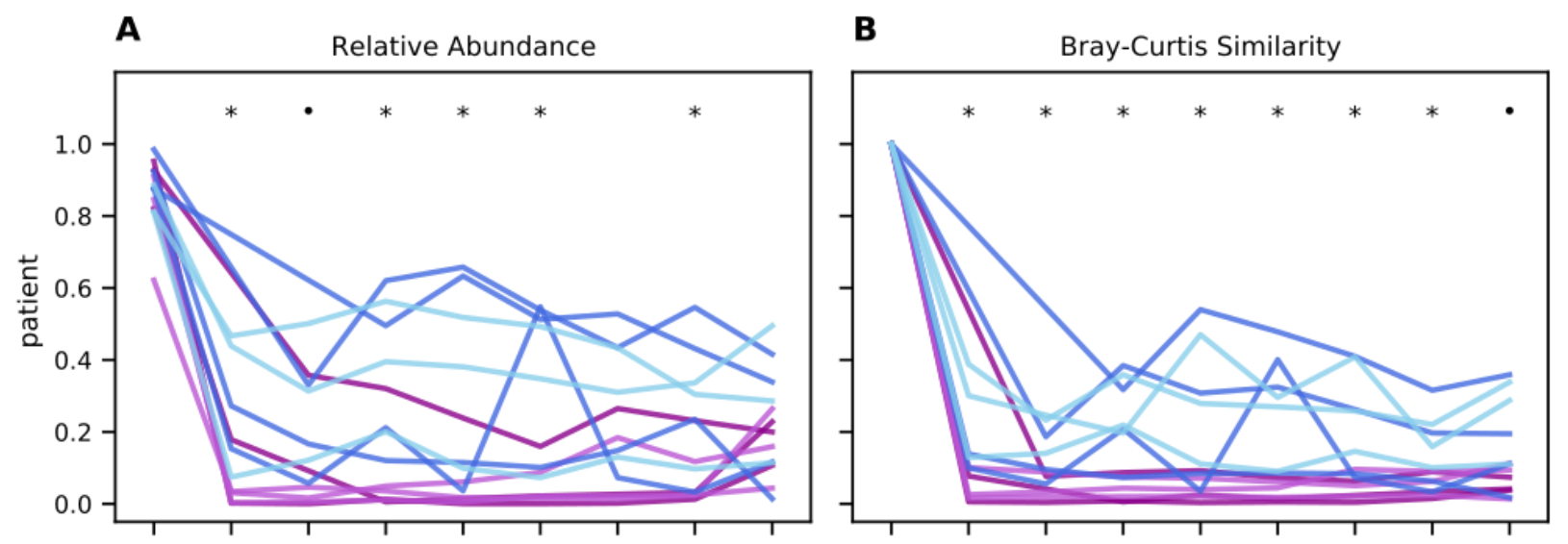

C

D
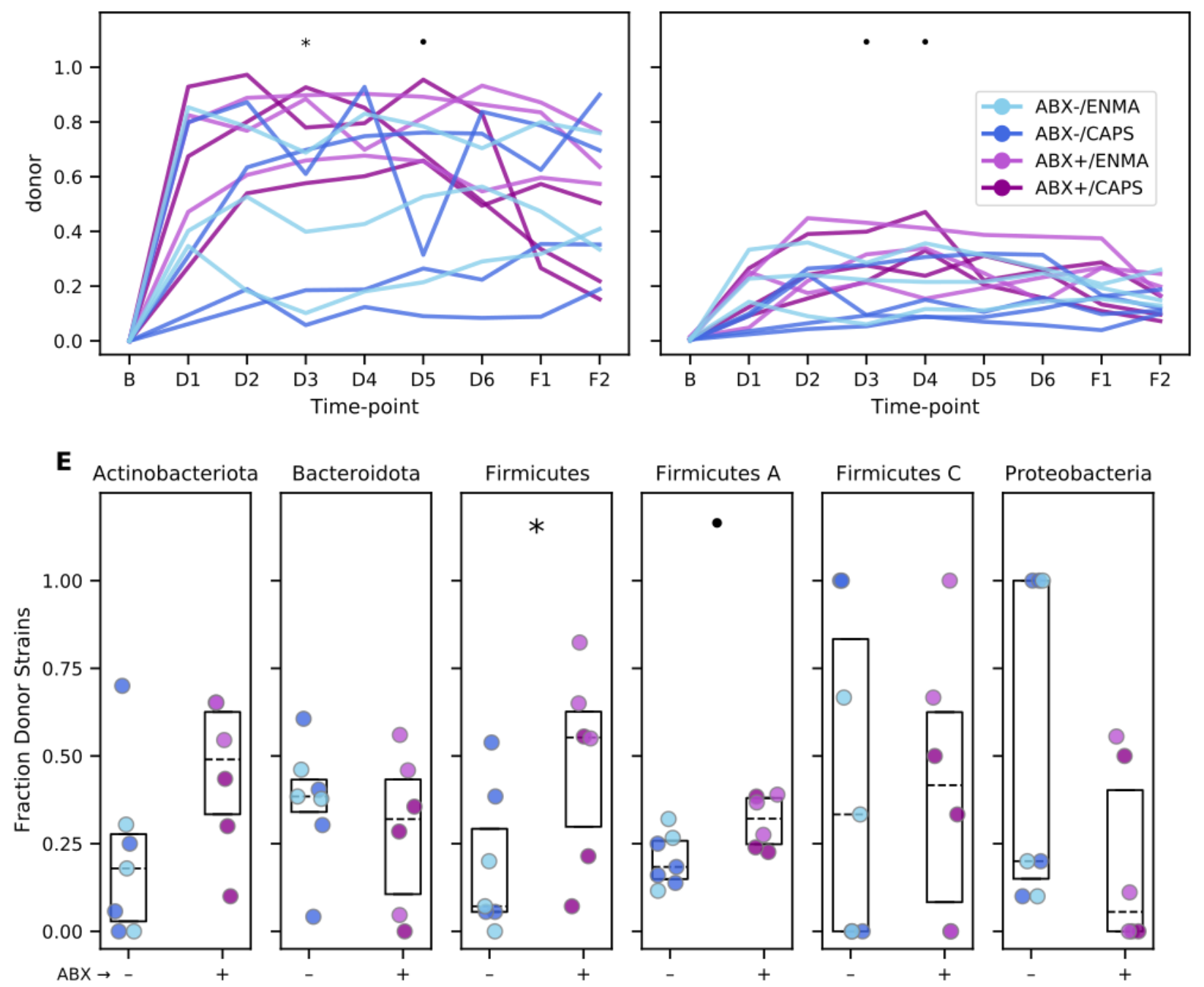

Figure 3: Greater community perturbation and engraftment of donor strains following FMT treatment in antibiotic-pretreated patients. $(\boldsymbol{A}, \boldsymbol{C})$ Abundance of strains specific to each patient's baseline sample (A) or specific to each donor sample $(C)$ relative to the patient's total strain populations over the course of treatment. $(B, D) B C$ similarity $(1$ - $B C$ dissimilarity) between each patient's sample and that patient's own baseline $(B)$ or their assigned donor (D). (E) Fraction of donor strains detected in each patient's fecal samples at F1. Each dot represents a patient, colors are as in $(A-D)$. Boxes span the interquartile range 
medRxiv preprint doi: https://doi.org/10.1101/2021.08.07.21261556; this version posted August 10, 2021. The copyright holder for this preprint (which was not certified by peer review) is the author/funder, who has granted medRxiv a license to display the preprint in perpetuity. It is made available under a CC-BY 4.0 International license.

with the median also marked (dotted line). In all panels, symbols indicate individual time points (A-D) and taxa $(E)$ with $p$-values less than $0.1(\bullet)$ or $0.05\left(^{*}\right)$ by MWU test for differences between patients who did or did not receive antibiotic pretreatment.

Not all bacterial clades were transferred at the same rate from donors to patients. We estimated the overall strain transfer rate as the fraction of all donor-specific strains, summed across all donor/patient pairs, that were subsequently found in patients at F1 (Fig. 3E). This transferability index differed between some of the most abundant phyla-here defined as in the Genome Taxonomy Database (GTDB) (37, 38) -from 29\% for Actinobacteriota (98 of 339 opportunities) and $26 \%$ for Firmicutes A (1138 of 4305 opportunities) to 34\% for Bacteroidota (362 of 1062 opportunities, significantly different from Firmicutes $A, p<0.001$, by two-sided Fisher exact test). Interestingly, the Verrucomicrobiota, represented exclusively by strains of Akkermansia muciniphila, had by far the lowest transfer rate at $2.9 \%$ (1 of 35 opportunities). Even taking into account the small number of donor-specific strains from the species, this was significantly below the rate for other phyla $(p=0.002,0.035$, and 0.011 for Actinobacteriota, Firmicutes $A$, and Proteobacteria, respectively, and $<0.001$ for Bacteroidota). A. muciniphila has been shown to be depleted in UC patients relative to healthy subjects (39), and to ameliorate colitis in a chemically induced mouse model (40). While we are hesitant to speculate based on this observation alone, FMT protocols optimized to transfer $A$. muciniphila might show increased remissions rates if the species indeed plays a role in recovery.

\section{Antibiotics modulate effects of FMT on the microbiome}

We next examined whether maintenance method, donor, and antibiotic pretreatment affected the outcomes of FMT.

Testing each treatment covariate while accounting for this repeated measures design, we found that samples taken during maintenance and follow-up time points from patients who had received antibiotic pretreatment had lower BC similarity to their own baseline $(p<0.001$ by LRT in the GEE framework), had a smaller total relative abundance of patients' baseline strains $(p<0.001)$, were more similar to donors $(p=0.015)$, and were composed of a larger relative abundance of their donors' strains $(p=0.015)$. Similarly, donor was also a significant predictor of all four outcomes: BC similarity to baseline $(p=0.021)$, BC similarity to donor $(p<0.001)$, relative abundance of baseline strains $(p<0.001)$, and relative abundance of donor strains $(p<0.001)$. When testing the effect of antibiotic pretreatment while also controlling for donor, only the BC similarity to baseline and fraction of baseline strains remained significant $(p=0.002$ and $p=0.005$, respectively), likely due to the small size of the data and the imbalance in the distribution of treatment arms across donors. Comparing repeated samples from patients that got different maintenance dose formulations showed a small effect $(\mathrm{p}=0.044)$ with slightly greater $B C$ similarity to donor for individuals who received enemas, but this effect was not sustained when controlling for donor. Tests carried out at individual time points showed similar patterns (Fig. 3AD), however, this approach does not harness the increased statistical power of combining multiple observations for each patient.

Overall, a slightly larger fraction of donor-specific bacterial strains were found at F1 in patients receiving antibiotic pretreatment, but this effect did not rise to the level of statistical significance $(p=0.134$ by MWU). Interestingly, antibiotic pretreatment did not affect the engraftment of all bacterial clades equally (Fig. 3E). When broken down at the phylum level, strains classified as Firmicutes and Firmicutes A-distinct phyla in the GTDB-both showed higher transmission from donors to patients in $A B X+$ arms ( $p=0.032$ and 0.054 , respectively). The phylum Actinobacteriota also shared this trend, although it did not approach statistical significance $(p=0.133)$, and we did not detect an effect for other abundant phyla. Comparisons between 
medRxiv preprint doi: https://doi.org/10.1101/2021.08.07.21261556; this version posted August 10, 2021. The copyright holder for this preprint (which was not certified by peer review) is the author/funder, who has granted medRxiv a license to display the preprint in perpetuity.

It is made available under a CC-BY 4.0 International license.

maintenance methods (CAPS vs. ENMA) did not reveal differences in strain engraftment for any of the abundant phyla. In total, these results suggest that antibiotic pretreatment increases the engraftment of donor strains, and is likely an effective strategy to optimize for this outcome after FMT.

\section{Changes in taxonomic profiles after FMT correlate with changes in functional gene and BA profiles.}

Given the dramatic transfer of donor taxa during FMT, we investigated the extent to which this taxonomic perturbation was concomitant with perturbations of functional gene and BA profiles. To do this, we performed pairwise Mantel tests (see Fig. 4A) among intra-patient dissimilarity matrices comparing taxonomic community composition at family, species, and strain levels to gene family coverages and BA profiles.

A

\section{Functional} (KO)

Family Species

Strain

ASV

B

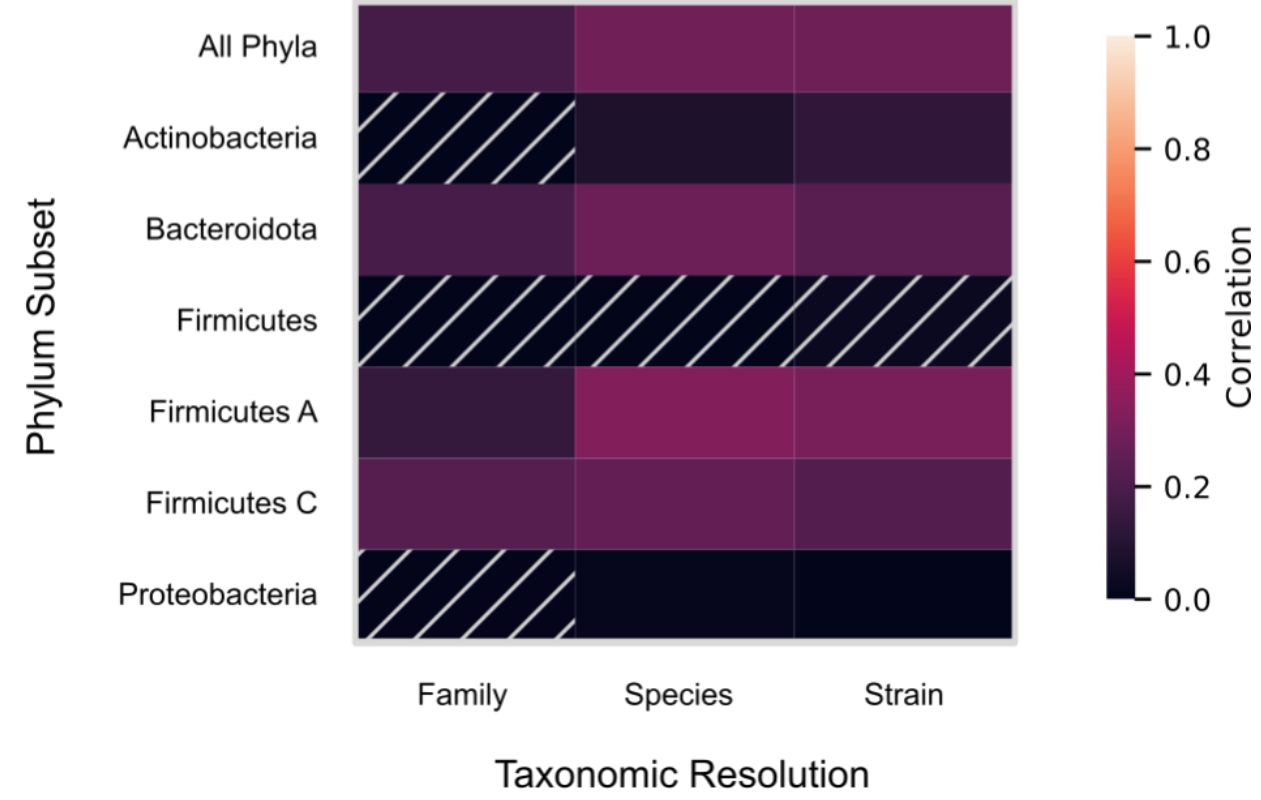

Figure 4: Changes across taxonomic, functional, and BA profiles are correlated. Heatmap tiles depict Pearson correlation coefficients between all within-patient pairwise dissimilarity scores, controlling for time, with brighter colors indicating a stronger association between profiles. Comparisons are for $(\boldsymbol{A})$ each 
medRxiv preprint doi: https://doi.org/10.1101/2021.08.07.21261556; this version posted August 10, 2021. The copyright holder for this preprint (which was not certified by peer review) is the author/funder, who has granted medRxiv a license to display the preprint in perpetuity. It is made available under a CC-BY 4.0 International license.

pairwise comparison between taxonomic and functional gene profiles with $B A$ and functional gene profiles, or (B) BAs, specifically, compared across taxonomic profiles at different resolutions ( $X$-axis) and phylum-level subsets ( $Y$-axis). Hatched cells indicate comparisons where $p$-values are $>0.05$ by Mantel permutation test ( $n=9999)$; all other comparisons are significant at or below this threshold.

All correlations with functional gene profiles were statistically significant with partial correlation coefficients greater than 0.5 after controlling for days since FMT. Likewise, the three taxonomic profiles also correlated with BA profiles. Changes in functional gene profiles were only weakly correlated with BA profiles (partial $R=0.09, p=0.045$ ). Although outside the scope of this study, we speculate that this correlation might be higher for the subset of KOs that are related to BA metabolism. Nonetheless, all four correlations together demonstrate that various changes to the microbiome are interrelated during and after FMT.

While the correlation between taxonomic and functional gene profiles increased at higher taxonomic levels (family > species > strain), the opposite was found for BA profiles (family < species $\approx$ strain). A partial Mantel test did not find a significant correlation with strains after controlling for species (partial $R=0.07, p=0.119$ ). The fact that family-level associations were weaker than associations at either species or strain levels suggests that intra-family differences in association with BAs are likely to be important.

To narrow down aspects of the microbiome with the strongest potential impact on BA profiles, we subsetted the taxonomic composition at the family, species, and strain levels for the six bacterial phyla with the highest average abundance across donors and patients at baseline: the Firmicutes A (54.0\%), Bacteroidota (18.3\%), Actinobacteriota (10.4\%), Firmicutes $(8.1 \%)$, Proteobacteria (3.6\%), and Firmicutes C (2.8\%). We then compared changes in each microbial community fraction to changes in BAs while controlling for time (Fig. 4B). We found that at each level most taxonomic subsets were significantly correlated with BA-profile dissimilarities. Interestingly, at the species level the strongest correlation with BAs was found with the highly abundant Firmicutes $A$ fraction. This is consistent with the limited phylogenetic distribution of $7 \alpha-$ dehydroxylation function to this clade (41), understood to be a key step in bacterial BA transformation. However, while for the Firmicutes A, Firmicutes C, Firmicutes, and Bacteroidota fractions the association is not stronger at strain-level resolution, the correlation for the Actinobacteriota fraction rose from $0.075(p=0.051)$ at the species resolution to $0.126(p=$ 0.013 ) at strain resolution. Consistent with this, there was a correlation between shifts in BA profiles and shifts in Actinobacteriota strain profiles even after controlling for the Actinobacteriota species profile (partial Mantel $R=0.125, p=0.038$ ), which could potentially be explained by greater intraspecific variation in BA transformation activity in this phylum, perhaps due to a heterogeneous distribution of bile salt hydrolases in the clade (42). This result further highlights the importance of strain-level analysis for understanding the drivers of functional differences in microbiomes during FMT.

\section{Discussion}

Here we have experimentally tested the effects of antibiotic pretreatment and maintenance dosing modalities on the clinical and microbiome impacts of FMT for UC. We collected and analyzed a comprehensive, longitudinal, multi-omics dataset, including clinical measurements, taxonomic and functional metagenomics, and BAs from fecal samples taken before, during, and after treatment. While not statistically significant at a traditional $p$-value threshold, we find a trend towards increased remission rates after FMT in patients receiving antibiotic pretreatment. Similarly, we find significantly increased transmission of donor microbiota after FMT in pretreated patients, and the possibility that pretreatment could result in a greater transfer of microbial functions. 
medRxiv preprint doi: https://doi.org/10.1101/2021.08.07.21261556; this version posted August 10, 2021. The copyright holder for this preprint (which was not certified by peer review) is the author/funder, who has granted medRxiv a license to display the preprint in perpetuity.

It is made available under a CC-BY 4.0 International license.

These results contribute to a growing literature on potential optimizations for FMT that increase efficacy, safety, and tolerability of the therapy. Importantly, in this study, maintenance dosing via capsules versus enemas lead to similar strain transmission and remission rates, consistent with previous findings on FMT to treat $C$. difficile infection $(15,18,43)$. Meta-analyses have shown an association between maintenance dosing and increased remission (6), although the frequency and duration has varied considerably, and previous studies with only two maintenance doses have also demonstrated the effectiveness of FMT therapy for UC (10). We observe rapid conversion of patients' microbiomes early in treatment, raising the interesting possibility that a shorter maintenance regimen may be sufficient to elicit sustained engraftment, although this will need to be tested experimentally in future work.

While our findings suggest that antibiotic pretreatment facilitates the sustained transfer of donor microbiota, and this was concomitant with a possible increase in efficacy, we did not find compelling support for the widely assumed importance of this microbial transfer for treatment efficacy. We also did not find clear evidence for differences in the effectiveness of material from different donors (e.g. as described in 44), although our study was not designed to find subtle effects of this type if they do exist.

This pilot study was limited by the small number of participants completing the full protocol, as well as the large number of primary and exploratory analyses. Reported statistical significance was not corrected for multiple testing. Given these limitations, many of the patterns identified here should be validated in larger designs. Of particular importance, future studies will need mechanisms to account for patients discontinuing the experimental treatment due to worsening symptoms. Interpretation of the metabolomic and metagenomic results presented here is limited-necessarily-by the inclusion of only those patients with a follow-up colonoscopy. Despite these shortcomings, the application of computational methods designed to maximize the value of our comprehensive, longitudinal dataset enabled the detection of differences between study arms in taxonomic and functional turnover, among other novel insights.

We find that the use of strain haplotypes inferred from SNP profiles (22) greatly improved the sensitivity of our transmission analysis. While this was expected given the large number of shared taxa at the species and 16S rRNA gene amplicon SNV levels, it is surprising that this improvement was possible without tuning hyper-parameters of the Strain Finder algorithm. Independent validation of the haplotypes and strain abundance estimates would be technically challenging, and is outside this study's scope. However, the conclusions detailed here-most of which result from comparisons of identically analyzed samples-are likely robust to variable accuracy of strain inferences. The SNP deconvolution approach was of particular value in this study, since other available methods for strain tracking (reviewed in 45) either require high quality strain reference sets (46), or use heuristics based on dissimilarities between metagenotypes that assume species have one dominant strain per sample (47) or ignore the possibility of rare strains (e.g. less than $10 \%$ in 48). None of these alternative approaches is optimal for the tracking of discrete strains in a study where donor and recipient communities are intentionally mixed through FMT. Continued development of haplotype deconvolution methods will empower further studies of strain-specific functions and ecological dynamics in FMT.

The conversion of primary bile salts into a diverse assortment of secondary BAs is a microbial process of particular interest in UC, among other conditions. Two findings from this study contribute to a better understanding of how BA profiles are affected by FMT. First, profiles clustered by patient but not significantly by donor. Subject-level clustering after FMT can be observed in prior work (49), and indicates that both host and microbial processing of BAs are remarkably stable; despite robust transfer of donor microbes, our protocol was unable to systematically modulate the concentrations of these metabolites. Second, we nonetheless saw 
medRxiv preprint doi: https://doi.org/10.1101/2021.08.07.21261556; this version posted August 10, 2021. The copyright holder for this preprint (which was not certified by peer review) is the author/funder, who has granted medRxiv a license to display the preprint in perpetuity.

It is made available under a CC-BY 4.0 International license.

that the magnitude of changes to BA profiles correlated with the extent of taxonomic turnover. These observations suggest that the donor microbiome indeed impacts the patient's BA profile, but that the direction of this effect may depend on properties of the patient and their microbiome. Together these results invite further inquiry into the role of BAs and other metabolites in UC, and how FMT might be harnessed to modulate them.

\section{Conclusions}

Here we have shown evidence for a potential increase in the remission of UC and the transmission of donor microbes during FMT in patients receiving antibiotic pretreatment. By contrast, we do not find a difference in efficacy or transmission due to the maintenance dosing protocol, suggesting that capsules may be a viable alternative to enemas. We observe patterns consistent with the hypothesis that increased transmission may result in improved outcomes, potentially due to changes in the composition and activity of the gut microbiome. This work demonstrates the increased sensitivity of strain-resolved metagenomic surveys in tracking transmission of donor microbiota, and presents a longitudinal, multi-modal characterization of the microbiome that can inform better-powered clinical trials designed to identify optimal treatment protocols for clinical use.

\section{Methods}

\section{Patient recruitment, ethics approval, and concurrent therapies}

Patients aged 18-64 years with a history of UC confirmed by endoscopy and pathology were recruited at a single academic center and were considered eligible if they had mild to moderate disease activity-a total Mayo score of 4-9 with endoscopic subscore of 1 or 2 assessed by flexible sigmoidoscopy or colonoscopy within 12 months of enrollment and reassessed at the time of initial colonoscopy for FMT delivery. Patients with prior colectomy, severe immunodeficiency, indeterminate colitis, severe UC or history of inflammation limited to distal proctitis (distal $5 \mathrm{~cm}$ ) were excluded from participation. See Supplementary Methods for full inclusion and exclusion criteria. Disease activity was assessed again at time of initial colonoscopy.

All participants were recruited between March 2017 and March 2020 and provided written informed consent for voluntary participation in this institutional review board-approved protocol (UCSF IRB study number: 16-20066). FMT was approved for use for this indication under FDA Investigational New Drug application (IND 16467). This study was registered at Clinicaltrials.gov (NCT03006809).

Concurrent therapies were allowed during the course of the trial as long as doses were stable (mesalamine $\times 4$ weeks, immunomodulators $\times 3$ months and biologics $\times 3$ months). However, steroids were minimized to an equivalent dose of no more than $10 \mathrm{mg}$ prednisone/day with forced weaning of $2.5 \mathrm{mg} /$ week during the study period. Additionally, rectal therapy was discontinued 30 days prior to study treatment and probiotics were held six weeks prior to administration of the first FMT dose.

\section{Study design and clinical details}

Participants were randomized into one of four arms by study coordinators by arbitrary selection of unlabeled paper envelopes containing assignments. Unlike study arms, donor material was assigned non-randomly based on availability. Study treatments were administered from September 2017 to March 2020, and the safety follow-up period continued for one year after the 
medRxiv preprint doi: https://doi.org/10.1101/2021.08.07.21261556; this version posted August 10, 2021. The copyright holder for this preprint (which was not certified by peer review) is the author/funder, who has granted medRxiv a license to display the preprint in perpetuity.

It is made available under a CC-BY 4.0 International license.

end of treatment. Patients assigned to $A B X+$ arms were pretreated with neomycin, vancomycin and metronidazole $500 \mathrm{mg}$ twice-daily for 5 days, followed by a one-day wash-out period. Patients then underwent colonoscopy to confirm eligibility, receiving their first FMT dose (250 $\mathrm{ml}$ ) during the procedure. Starting one week later, and over the next six weeks, patients received maintenance doses, 30 capsules weekly for patients in the CAPS arm, or a 60-mL enema weekly for patients in the ENMA arm. Donor stool was provided by OpenBiome, whose screening methods have been previously described (50). Participants were assigned a single donor for all doses throughout the study period. Deviations from the prescribed design are detailed in Supplementary Table 7.

To minimize invasiveness, baseline endoscopy for patients in $\mathrm{ABX}+$ arms was performed after patients received antibiotics. Past studies have considered antibiotics as a treatment for UC, and conceivably these patients may have already experienced amelioration of symptoms after their enrollment. This possible confounding seems unlikely, however, both because past work has largely not supported the effectiveness of antibiotics (51-54), and due to the short duration of antibiotic treatment in this study.

Baseline data including serum inflammatory markers, infectious stool studies and fecal calprotectin were obtained prior to D0 (the initial FMT) and F1. A full list of clinical assessments is available in Supplementary Table 8. Colonoscopy for endoscopic restaging and repeat biopsies was performed at D0. Adverse events were solicited the day after colonoscopy, weekly during the course of maintenance therapy and then monthly until 6 months after initial FMT and again at 12 months after initial FMT. Remission at F1 was defined as a total Mayo score $\leq 2$ and endoscopic improvement by $\geq 1$ point.

Detailed descriptions of fecal sample collection and processing are included in the Supplementary Methods. Lists of which samples were collected and used for 16S rRNA gene V4 region and shotgun metagenomic library sequencing, as well as untargeted metabolomics are listed in Supplementary Tables 3-6, respectively.

\section{Data processing and reproducibility}

\section{Environment and pipeline}

Sequence and metabolite data were analyzed using a reproducible pipeline implemented with the Snakemake workflow manager (55). Our computational environment is available as a Docker container <https://hub.docker.com/repository/docker/bsmith89/compbio> (56) and uses Conda (57) for most software installations. Final analyses were performed and visualized in Python and R using the Jupyter Notebook environment (58), and a rendering of our analysis notebook is available as a Supplementary Note. Where randomization was used, random number generators were seeded with a fixed value for reproducibility. Detailed descriptions of the data analysis pipeline is included in the Supplementary Methods.

\section{Taxonomic profiling}

We applied GT-PRO (36) to count the occurences of reads containing exact k-mers representative of previously identified, per-species, bi-allelic positions in the UHGG (59), a comprehensive database of human gut bacterial reference genomes. The coverage (sum of major and minor allele counts) of these SNP sites was then used to estimate the per-sample abundance of each species as the mean of all position coverages observed in any sample, after discarding the $5 \%$ highest and lowest coverage positions. This trimmed mean makes our coverage estimate robust to anomalously high or low coverage positions. Relative abundances 
medRxiv preprint doi: https://doi.org/10.1101/2021.08.07.21261556; this version posted August 10, 2021. The copyright holder for this preprint (which was not certified by peer review) is the author/funder, who has granted medRxiv a license to display the preprint in perpetuity.

It is made available under a CC-BY 4.0 International license.

were then calculated as the coverage of each species divided by the total coverage of all species estimated for that sample.

The GT-PRO metagenotypes were also used to estimate the abundance of haplotypes (referred to as strains above) in each species. This was accomplished using the tool Strain Finder (22), run on the major and minor allele coverages at 100 randomly selected positions. Importantly, due to the scope of this study and computational limitations, we did not rigorously estimate the optimal number of strains in each sample and limited Strain Finder runtime to 60 minutes per species. We therefore may not have reached a global optimum in all cases. Instead we allowed for a maximum of 20 haplotypes to be fit for each species. Fitting the model in this way could result in inferred haplotypes grouping or splitting true strain abundances more than if we had also optimized the number of haplotypes and run the random search algorithm for longer. While this may have reduced the sensitivity of our analyses, we do not believe that it limited the veracity of any of our conclusions, which were primarily based on overall dissimilarity scores between samples and tracking of strains in donor/patient pairs. Fractional abundances of each strain inferred by strain-finder were then scaled by the previously estimated, per-sample species coverages to produce an estimate of strain coverage in each sample.

We demonstrate improvements in sensitivity to transfer events using this approach in a Supplementary Note.

\section{Statistical analysis}

\section{Patient/sample exclusion and efficacy statistics}

For all analyses, as many patients and samples were included as possible. For instance, engraftment comparisons at individual time points include all available samples, ignoring patients with missing samples. Metagenomic data for one sample with fewer than $1 \mathrm{e} 6$ reads was dropped from analysis, as this is much less than all others. Detailed lists of which microbiome profiles were collected for each patient are available as Supplementary Tables 3-6.

Patients were included in remission comparisons if they had both baseline and follow-up colonoscopies/Mayo scores. Two additional patients that had withdrawn without follow-up colonoscopies were also included as "non-remissions" because they withdrew due to worsening symptoms. Differences in remission rates between treatment groups were calculated for patients pooled into ABX-/ABX+ or CAPS/ENMA groups, and tested using a two-sided Fisher exact test.

Given the small sample size and exploratory analyses, statistical significance was not corrected for multiple testing, throughout.

\section{Profile comparisons: Dissimilarities, ordination, clustering analysis}

Donor taxonomic and functional profiles were calculated by summing coverage across all samples obtained from that donor-10, 31, and 1 samples with metagenomes for D0044, D0097, and D0485, respectively. For microbial taxonomic profiles, inferred strain coverages in each sample were normalized to sum to one. Then, for higher taxonomic levels, strain relative abundances were summed within assignments provided by the UHGG database, which are based on the GTDB $(37,38)$. Likewise, for phylum-specific analyses, taxonomic profiles were partitioned based on the UHGG assignment and then renormalized to sum to one. Ordination and cluster analyses were performed on pairwise dissimilarities between sample profiles. For all taxonomic profiles the BC dissimilarity was used, while for functional gene and BA profilesneither of which is strictly compositional-we used the cosine dissimilarity instead. Ordinations 
medRxiv preprint doi: https://doi.org/10.1101/2021.08.07.21261556; this version posted August 10, 2021. The copyright holder for this preprint (which was not certified by peer review) is the author/funder, who has granted medRxiv a license to display the preprint in perpetuity.

It is made available under a CC-BY 4.0 International license.

were performed using non-metric multidimensional scaling as implemented in the Scikit-Learn package for Python (60). Clustering of profiles by donor and patient was tested with ANOSIM using 9999 permutations to calculate a $p$-value.

\section{Longitudinal data analysis}

For response variables with repeated measures on the same patients, the effects of treatment parameters were tested under the general estimating equations framework (implemented in the geepack package for $\mathrm{R}(61)$ ) using a robust, autoregressive covariance structure parameterized by the temporal order of samples. Individual tests were carried out for the effects of antibiotic pretreatment, maintenance dosing method, and donor identity against a null model that included only weeks since initial FMT. Where indicated, donor identity was also included in the null model to test for effects of treatment parameters above and beyond this sometimes confounding random effect.

\section{Mantel tests}

Correlations between dissimilarities for pairs of profiles were tested with the Mantel and partial Mantel tests. Specifically, dissimilarity matrices were calculated for baseline, maintenance, and follow-up samples from each patient (post-antibiotic samples were excluded). These matrices were combined as a block-diagonal matrix; no values were included for inter-patient comparisons. Mantel tests were performed using pearson correlations or partial correlations, and $p$-values were calculated from 9999 permutations. For tests controlling for time, partial correlations were based on the square-root of the time in days between samples being collected. While shortcomings of the Mantel test have been documented (62), the method has been applied in past studies linking different features of the microbiome (63). In addition, spatial and temporal autocorrelation is expected to result in decreased power, making this approach a conservative measure of associations across data types.

\section{Endmatter}

\section{Author Contributions}

- BJS: conceptualization, data curation, formal analysis, methodology, software, visualization, writing - original draft, writing - review \& editing.

- YMP: methodology, investigation, writing - review \& editing.

- KSP: conceptualization, methodology, writing - review \& editing, funding acquisition, supervision

- $\quad$ LAS: Project administration, investigation, resources, writing - review and editing

- $\quad \mathrm{NE}$ : conceptualization, patient recruitment/enrollment, methodology, supervision, funding acquisition, writing- review and editing

- $\quad \mathrm{MZ}$ : project administration, data collection, writing - review and editing

- $\quad$ ZK: conceptualization, methodology, writing - review and editing

- JPT: patient recruitment, review and editing

- $\quad$ AM: funding acquisition, conceptualization

- $\quad$ BZ: data curation, methodology, formal analysis, writing - original draft, writing - review and editing

- $\quad$ SVL: funding acquisition, conceptualization, supervision, writing - review and editing 
medRxiv preprint doi: https://doi.org/10.1101/2021.08.07.21261556; this version posted August 10, 2021. The copyright holder for this preprint (which was not certified by peer review) is the author/funder, who has granted medRxiv a license to display the preprint in perpetuity.

\section{Acknowledgements}

- $\quad$ BJS and BZ are supported by funding from the National Institutes of Health grant number 5T32DK007007.

- $\quad$ KSP and BJS were supported by funding from National Science Foundation grant number 1563159, Chan Zuckerberg Biohub, and Gladstone Institutes.

- $\quad \mathrm{NE}, \mathrm{MZ}$ and YMP were supported by funding from the Kenneth Rainin Foundation

- Kole Lynch and Doug Fadrosh prepared libraries and sequenced 16S rRNA gene amplicons.

- $\quad$ Françoise Chanut provided editorial support.

\section{Competing Interests}

- $\quad$ YMP is an employee of Symbiome, Inc.

- $\quad$ ZK is an employee/shareholder at Finch Therapeutics

- $\quad$ SVL is co-founder and shareholder of Siolta Therapeutics, Inc. and serves as both a consultant and a member of its Board of Directors.

- KSP is on the scientific advisory board of Phylagen.

- NE has received research support from Finch Therapeutics and Assembly Biosciences, and has been a consultant for Federation Bio and Ferring Pharmaceuticals.

- All other authors declare no competing interests

\section{Data availability}

Amplicon sequences from the 16S rRNA gene and metagenomic sequences with human reads removed were uploaded to the SRA under BioProject PRJNA737472. All code and metadata needed to reproduce our results are available at <https://github.com/bsmith89/ucfmt2>. 
medRxiv preprint doi: https://doi.org/10.1101/2021.08.07.21261556; this version posted August 10, 2021. The copyright holder for this preprint (which was not certified by peer review) is the author/funder, who has granted medRxiv a license to display the preprint in perpetuity.

It is made available under a CC-BY 4.0 International license.

\section{Supplementary Information}

\section{Supplementary Note: Analysis Notebook}

Static rendering of Jupyter notebook with analysis/plotting of relevant results.

CodeNotebook.html

\section{Supplementary Results: Patient Demographics}

Table 1: Summary of demographics for 22 patients included in efficacy statistics

SupplementaryTabless $1-8 \cdot x l s x$

\section{Supplementary Results: Adverse Events}

Table 2: Summary of adverse events for all patients enrolled. Numbers indicate number of patients experiencing one or more events of each type. Where events are on a three point scale, higher values mean more severe events.

SupplementaryTabless1-8.xlsx

\section{Supplementary Table: Samples and Microbiome Profiles Collected by Patient}

Table 3: List of fecal samples collected.

SupplementaryTabless1-8.xlsx

Table 4: List of $16 S$ rRNA gene libraries sequenced.

SupplementaryTabless1-8.xlsx

Table 5: List of shotgun metagenomic libraries sequenced.

SupplementaryTabless1-8.xlsx

Table 6: List of metabolomic profiles collected.

SupplementaryTabless1-8.xlsx

\section{Supplementary Results: Patients Deviating from Initial Study Design}

Table 7: Summary of relevant deviations from main protocol.

SupplementaryTabless1-8.xlsx

Supplementary Data: Ordinations of microbiome profiles colored by patient 
medRxiv preprint doi: https://doi.org/10.1101/2021.08.07.21261556; this version posted August 10, 2021. The copyright holder for this preprint (which was not certified by peer review) is the author/funder, who has granted medRxiv a license to display the preprint in perpetuity.

It is made available under a CC-BY 4.0 International license.

A

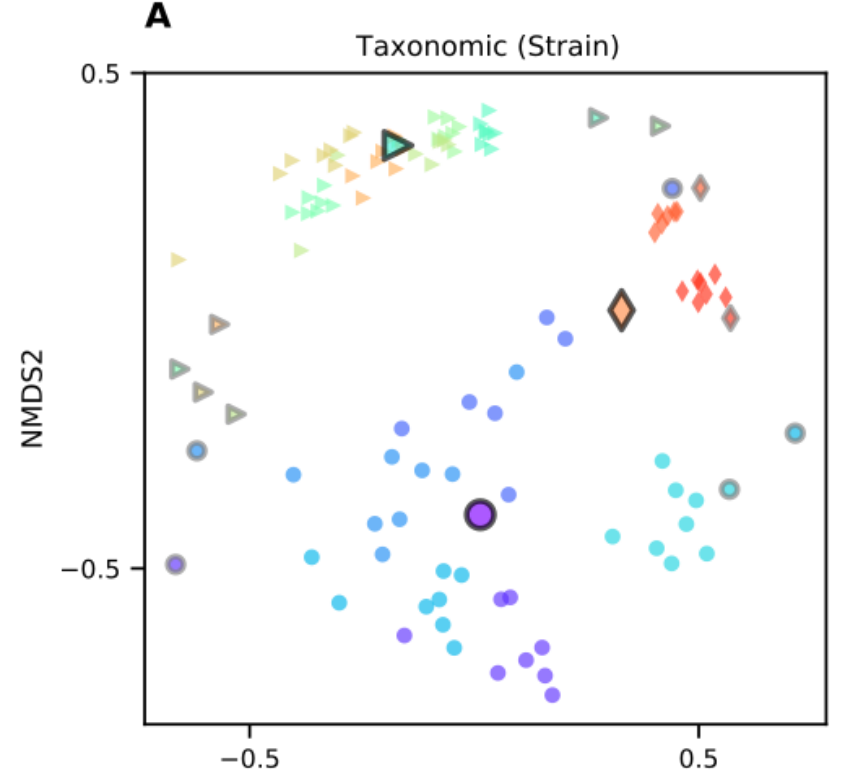

C

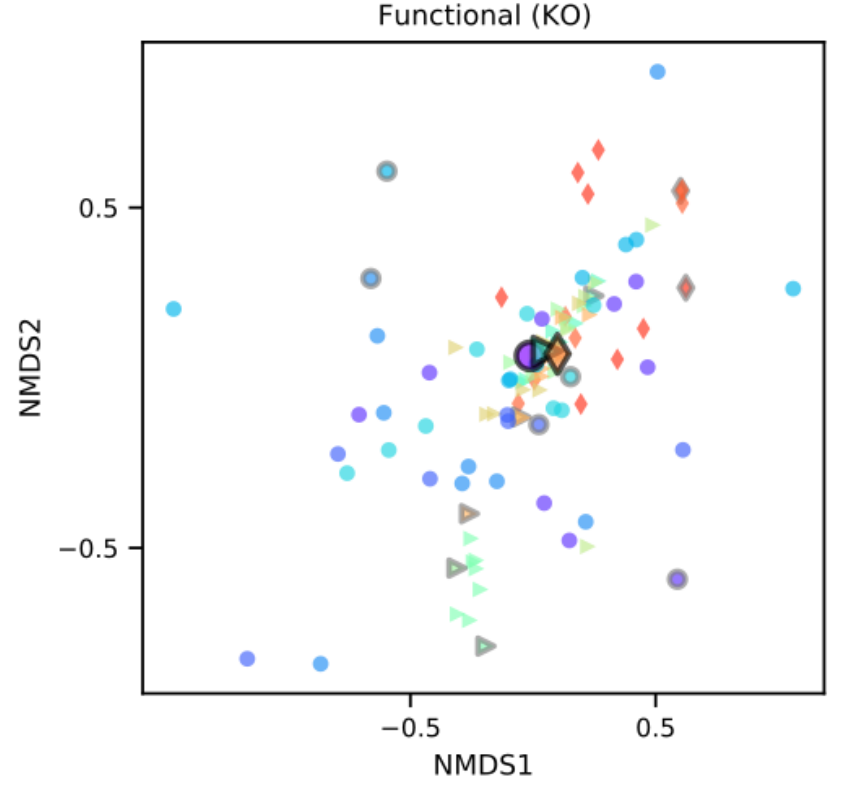

B

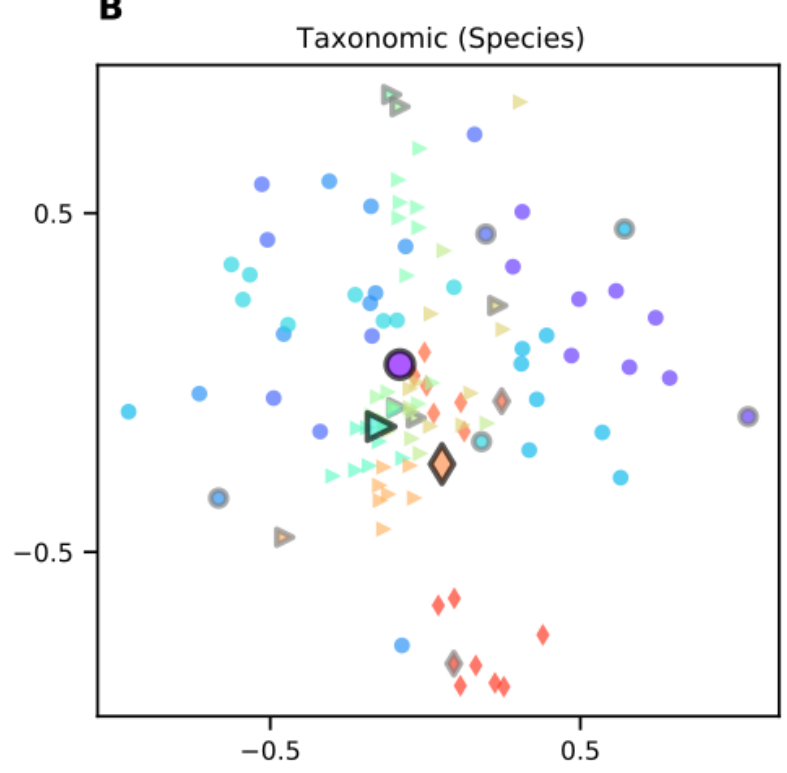

D

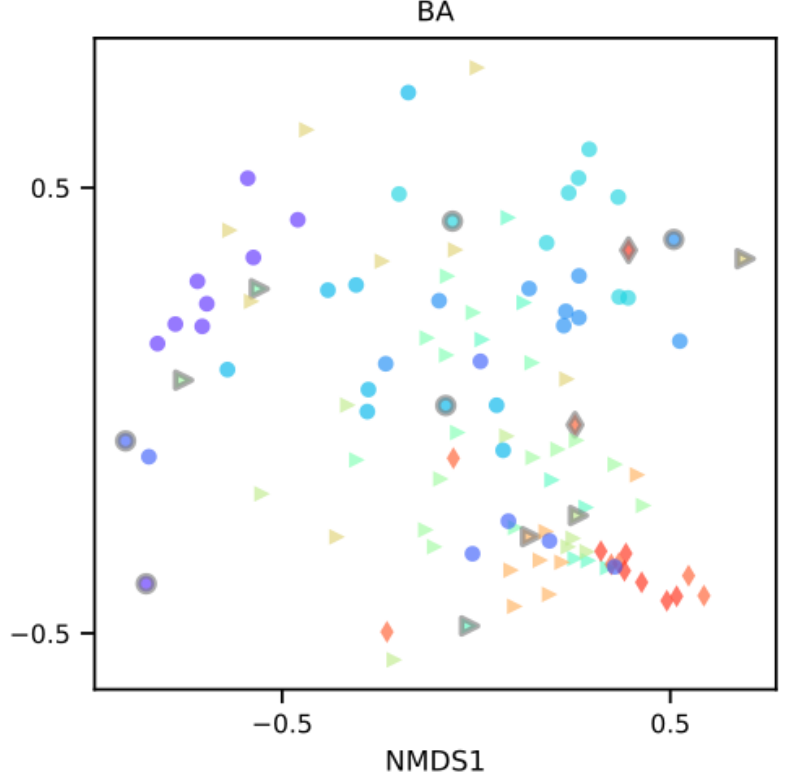

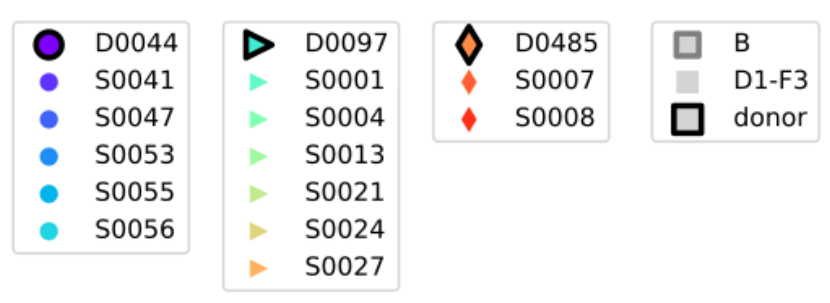

Figure 5: Clustering of taxonomic, functional, and BA profiles across time points. Ordinations are calculated and plotted as in Fig. 2. For (A-C) datatypes where donor samples were also profiled, larger points with black outlines represent the mean of all samples from that donor. Samples from each subject are differentiated by color and shape as indicated in the legend (bottom left). Patients' baseline samples are outlined in black. The same four ordinations colored by assigned donors are available as Fig. $2 A-D$. 
medRxiv preprint doi: https://doi.org/10.1101/2021.08.07.21261556; this version posted August 10, 2021. The copyright holder for this preprint (which was not certified by peer review) is the author/funder, who has granted medRxiv a license to display the preprint in perpetuity.

It is made available under a CC-BY 4.0 International license .

\section{Supplementary Data: Shared ASVs/Species/Strains across Donors}

Comparing taxa across donors presents one way to evaluate the effect of taxonomic resolution on the sensitivity of tracking transfers between individuals. That very few strains are found to be shared across donor communities (see Supplementary Fig. 5) indicates that false positivesnon-transfer of a donor strain incorrectly inferred to be a transfer-are infrequent.

ASV (16S)

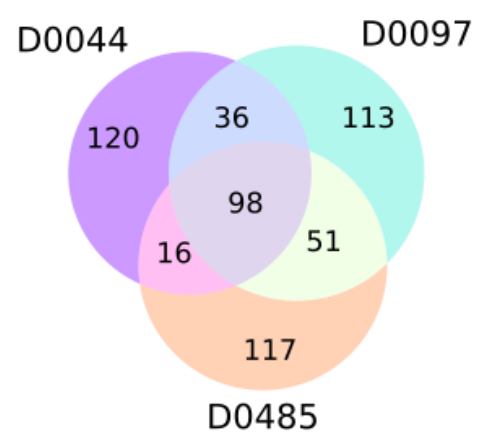

Species

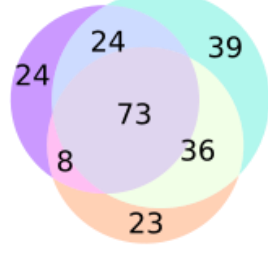

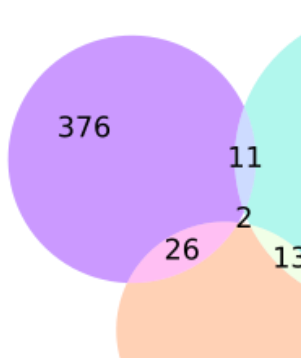

277

Figure 6: Overlap between taxa detected in three donors shows that strain-level taxonomic resolution increases sensitivity and specificity of engraftment detection. Venn diagrams depict relationships between sets of taxa detected in donor samples, and numbers indicate the size of the respective sets. Taxa were considered to be detected in a donor if their mean relative abundance across that donor's samples was greater than $0.01 \%$. Circles are colored by donor as in Fig. 2. Species composition was estimated from metagenomes based on the mean coverage reported by GT-PRO (36), and was further partitioned into strain composition based on haplotype deconvolution with Strain Finder (22).

\section{Supplementary Methods: Detailed Patient Inclusion/Exclusion Criteria}

\section{Inclusion Criteria}

- $\quad$ Patients with history of mild to moderate Ulcerative Colitis confirmed by endoscopy and pathology.

- Total Mayo score 4-9, endoscopic subscore $\geq 1$; patients who have not had endoscopic evaluation within one year of enrollment will have flexible sigmoidoscopy for evaluation.

- Age $18-64$ and deemed otherwise healthy at the discretion of the investigator.

- Concurrent therapies with mesalamine (stable $x 4$ weeks), immunomodulators (stable $x$ 3 months), and biologic agents (stable $\times 3$ months) will be allowed to continue during study.

- $\quad$ Prednisone must be $\leq 10 \mathrm{mg} /$ day at the time of treatment and will be weaned by 2.5 $\mathrm{mg} /$ week during the study period.

\section{Exclusion Criteria}

- $\quad$ Severe or refractory UC defined as Mayo score $\geq 10$, endoscopic disease activity score 3

- Untreated enteric infection (positive stool test for any of the following: Clostridium difficile, Salmonella, Shigella, Yersinia, Campylobacter, enteropathogenic E. coli or other enteric infection at the discretion of the investigator.

- History of colectomy

- $\quad$ Disease limited to distal proctitis (distal $5 \mathrm{~cm}$ )

- $\quad$ Patients taking probiotics within six weeks of planned FMT therapy. 
medRxiv preprint doi: https://doi.org/10.1101/2021.08.07.21261556; this version posted August 10, 2021. The copyright holder for this preprint (which was not certified by peer review) is the author/funder, who has granted medRxiv a license to display the preprint in perpetuity.

It is made available under a CC-BY 4.0 International license .

- Severe immunodeficiency, inherited or acquired (e.g. HIV, chemotherapy or radiation therapy)

- $\quad$ Patients with the following laboratory abnormalities: absolute neutrophil count (ANC) < $1000 / \mu$ l, platelets $<50 \times 10^{\wedge} 9 / \mathrm{L}$, hemoglobin $<6.5 \mathrm{~g} / \mathrm{dL}$.

- History of anaphylaxis (severe allergic reaction) to food allergens (e.g. tree nuts, shellfish)

- Dysphagia (orophyaryngeal, esophageal, functional, neuromuscular)

- History of recurrent aspiration episodes

- Documented severe gastroparesis

- Active intestinal obstruction

- Patients with renal insufficiency (GFR $<50 \mathrm{ml} / \mathrm{min}$ )

- $\quad$ Allergy to the following generally regarded as safe ingredients (GRAS): glycerol, acid resistant HPMC, gellan gum, cocoa butter, titanium dioxide

- $\quad$ Adverse event attributable to any previous FMT

- Allergy/intolerance to proton pump inhibitor therapy

- $\quad$ Allergy/intolerance to vancomycin, metronidazole, or neomycin.

- $\quad$ Non-steroidal inflammatory medications (NSAIDs) as long-term treatment, defined as use for at least 4 days a week each month.

- Cholestyramine use

- $\quad$ Any condition in which the investigator thinks the FMT treatment may pose a health risk (e.g. severely immunocompromised)

- $\quad$ Simultaneous participation in another interventional clinical trial

- $\quad$ Patients who are pregnant, breast feeding or planning pregnancy during study trial period.

- $\quad$ During the trial period until one week after the trial end: Non-use of appropriate contraceptives in females of childbearing potential (e.g. condoms, intrauterine device (IUD), hormonal contraception, or other means considered adequate by the responsible investigator) or in males with a child-fathering potential (condoms, or other means considered adequate by the responsible investigator during treatment) or well-founded doubt about the patient's cooperation

- $\quad$ Patients with any other significant medical condition that could confound or interfere with evaluation of safety, tolerability or prevent compliance with the study protocol at the discretion of the investigator

- $\quad$ Life expectancy $<6$ months

\section{Supplementary Methods: Stool Sampling Instructions to Patients}

Instructions to patients for stool self-sampling.

SelfSampling ppdf

Supplementary Methods: Clinical Laboratory Assessments

Table 8: List of clinical laboratory assessments

SupplementaryTabless1-8.xlsx

\section{Supplementary Methods: Sample Processing}


medRxiv preprint doi: https://doi.org/10.1101/2021.08.07.21261556; this version posted August 10, 2021. The copyright holder for this preprint (which was not certified by peer review) is the author/funder, who has granted medRxiv a license to display the preprint in perpetuity. It is made available under a CC-BY 4.0 International license.

\section{Sample collection and DNA extraction}

Patients were instructed to collect a stool sample into provided sample vials (Sarstedt faeces tubes cat. no. 80.734.311) before each study visit and either bring it refrigerated to our clinic inperson or send it with a frozen cool pack via overnight courier. Upon delivery, stool specimens were stored at $-80^{\circ} \mathrm{C}$ until their analysis.

DNA extraction from fecal samples was performed using the modified cetyltrimethylammonium bromide (CTAB) as previously described (64). In brief, $\sim 0.3 \mathrm{~g}$ aliquot was taken from each frozen stool sample and suspended in $500 \mu \mathrm{L}$ CTAB extraction buffer in a Lysing Matrix E tube (MP Biomedicals) by vortexing, followed by incubation for 15 minutes at $65^{\circ} \mathrm{C}$. After adding 500 $\mu \mathrm{L}$ phenol:chloroform:isoamyl alcohol (25:24:1), the solution underwent bead-beating $(5.5 \mathrm{~m} / \mathrm{s}$ for 30 seconds), followed by centrifugation $\left(16,000 \mathrm{~g}\right.$ for 5 minutes at $\left.4{ }^{\circ} \mathrm{C}\right)$. The resulting aqueous phase (approximately $400 \mu \mathrm{L}$ ) was transferred to a new $2 \mathrm{~mL} 96$-well plate. An additional $500 \mu \mathrm{L}$ CTAB extraction buffer was added to the fecal aliquot and both the beadbeating and centrifugation steps were repeated, resulting in approximately $800 \mu \mathrm{L}$. An equal volume of chloroform was added and the solution was mixed and centrifuged $(3,000 \mathrm{~g}$ for 10 minutes). The aqueous phase (approximately $600 \mu \mathrm{l}$ ) was transferred to another $2 \mathrm{~mL} 96$-well plate, combined with 2-volume polyethylene glycol and stored at $4{ }^{\circ} \mathrm{C}$ overnight to precipitate DNA. Samples were then centrifuged (3,000 g for 60 minutes) to pellet DNA, washed twice with cold $70 \% \mathrm{EtOH}$, resuspended in sterile water and diluted to $10 \mathrm{ng} \mathrm{DNA} / \mu \mathrm{L}$ (Qubit dsDNA BR Assay Kit; ThermoFisher Scientific, MA)

\section{Sequencing}

For $16 \mathrm{~S}$ rRNA gene profiling, The V4 region was amplified as previously described (64). PCR reactions were performed with $0.625 \mathrm{U}$ Hot Start ExTaq and $1 \mathrm{x}$ buffer, $200 \mu \mathrm{M}$ dNTPs, 0.56 $\mu \mathrm{L} / \mu \mathrm{L}$ BSA, $0.4 \mu \mathrm{M}$ each forward (F515) and reverse (R806) primers in triplicate $25 \mu \mathrm{L}$ reactions containing 10ng of template gDNA. Thermal cycling was set at: $98^{\circ} \mathrm{C}$ for 2 minutes, 30 rounds of $98^{\circ} \mathrm{C}$ for $20 \mathrm{sec}, 50^{\circ} \mathrm{C}$ for $30 \mathrm{sec}, 72{ }^{\circ} \mathrm{C}$ for $45 \mathrm{sec}$, and a final extension at $72{ }^{\circ} \mathrm{C}$ for 10 minutes. Amplicons were normalized (SequalPrep Normalization Plate Kit; ThermoFisher Scientific, MA), quantified (Qubit dsDNA BR Assay Kit; ThermoFisher Scientific, MA), pooled in equimolar concentrations, purified (Agencourt AMPure XP System; Beckman-Coulter), quantified (KAPA Library Quantification Kit; KAPA Biosystems), and diluted to 2 nM. Equimolar PhiX spike-in control was added at $40 \%$ final volume, and the samples were sequenced on an Illumina NextSeq 500 Platform.

For metagenomic sequencing, an aliquot of the extracted DNA was sent to QB3 at the University of California, Berkeley <https://qb3.berkeley.edu/> for sequencing on the NovaSeq 6000 platform using the 150PE Flow Cell S4 format.

\section{Metabolomics}

For metabolomics profiling, 112 fecal samples $(200 \mathrm{mg}$ ) were provided to Metabolon (Durham, NC) who performed Ultrahigh Performance Liquid Chromotography/Tandem Mass Spectrometry (UPLC-MS/MS) and Gas Chromatography-Mass Spectrometry (GC-MS) based on standardized published protocol < http://www. metabolon.com/>. Detected molecules were identified through Metabolon's library of purified standards, which encompasses $>3,300$ commercially available compounds. This yielded 1050 distinct metabolites among the samples, from which the 51 metabolites identified as primary and secondary bile acids were analyzed for this study. For each identified BA, peak intensities were normalized by the root mean squared intensity of that peak across samples before downstream analysis. 
medRxiv preprint doi: https://doi.org/10.1101/2021.08.07.21261556; this version posted August 10, 2021. The copyright holder for this preprint (which was not certified by peer review) is the author/funder, who has granted medRxiv a license to display the preprint in perpetuity.

It is made available under a CC-BY 4.0 International license.

\section{Supplementary Methods: Microbiome profiling}

\section{S rRNA gene amplicon analysis}

Raw amplicon sequencing data was processed as in (64). Briefly, sequencer output was converted to fastq with bcl2fastq v2.16.0.10

<https://support.illumina.com/sequencing/sequencing_software/bcl2fastq-conversionsoftware. $h$ tml> and demultiplexed by barcode with QIIME (65). Quality-filtering via DADA2 (66) was performed using the recommended settings with the following adjustments - maximum expected errors allowed $\leq 3$, truncation length of 150 bases for R1 and 140 for R2; chimeric sequences were found using minFoldParentOverAbundance $=8$. Taxonomy was assigned with SILVA database V132 $(67,68)$ to amplicon sequence variants (ASV). Contaminant ASV were identified with the decontam (69) package for R. ASV with $>2 \%$ of total read sums contributed by controls and those with $<0.001 \%$ total read count across all samples were excluded. A phylogenetic tree was constructed using the phangorn $(70,71)$, msa (72), and DECIPHER (73) packages for $\mathrm{R}$. Amplicon sequencing resulted in an average of $3.4 \mathrm{e} 5$ paired reads per sample after processing.

\section{Metagenomic reads pre-processing}

Metagenomic sequences were deduplicated using FastUniq (74), any contaminating adapter sequence removed using Scythe (75), and then quality trimmed with Sickle (76). Any cleaned reads that mapped to the human reference genome (GRCh38 77) using Bowtie2 (78) were removed. Shotgun metagenomic sequencing resulted in $4.9 \mathrm{e} 7$ paired reads per sample after processing.

\section{Functional gene profiling}

Reads were annotated with presumed functions by first identifying homology to the UHGP-50 (50\% identity clusters, (59)) reference database using DIAMOND (79), a fast implementation of the BLASTX algorithm (80). All top hits to this database were tallied for each sample. UHGP-50 hits were subsequently annotated with KEGG Orthology (KO) numbers based on assignments previously generated for the UHGP using EggNOG-mapper (81). Tallies of reads mapping to these annotations were not corrected for gene length.

\section{References}

1. Yalchin M, Segal JP, Mullish BH, Quraishi MN, lqbal TH, Marchesi JR, Hart AL. 2019. Gaps in knowledge and future directions for the use of faecal microbiota transplant in the treatment of inflammatory bowel disease. Therap Adv Gastroenterol 12:1756284819891038. doi:10.1177/1756284819891038.

2. Lopetuso LR, laniro G, Allegretti JR, Bibbò S, Gasbarrini A, Scaldaferri F, Cammarota G. 2020. Fecal transplantation for ulcerative colitis: Current evidence and future applications. Expert Opin Biol Ther 20:343-351. doi:10.1080/14712598.2020.1733964.

3. Paramsothy S, Paramsothy R, Rubin DT, Kamm MA, Kaakoush NO, Mitchell HM, Castaño-Rodríguez N. 2017. Faecal Microbiota Transplantation for Inflammatory Bowel Disease: A Systematic Review and Meta-analysis. J Crohns Colitis 11:1180-1199. doi:10.1093/ecco-jcc/jjx063. 
medRxiv preprint doi: https://doi.org/10.1101/2021.08.07.21261556; this version posted August 10, 2021. The copyright holder for this preprint (which was not certified by peer review) is the author/funder, who has granted medRxiv a license to display the preprint in perpetuity. It is made available under a CC-BY 4.0 International license .

4. Costello SP, Soo W, Bryant RV, Jairath V, Hart AL, Andrews JM. 2017. Systematic review with meta-analysis: Faecal microbiota transplantation for the induction of remission for active ulcerative colitis. Aliment Pharmacol Ther 46:213-224. doi:10.1111/apt.14173.

5. Lam TJ, Ye Y. 2019. CRISPRs for Strain Tracking and Their Application to Microbiota Transplantation Data Analysis. CRISPR J 2:41-50. doi:10.1089/crispr.2018.0046.

6. Mocanu V, Rajaruban S, Dang J, Kung JY, Deehan EC, Madsen KL. 2021. Repeated Fecal Microbial Transplantations and Antibiotic Pre-Treatment Are Linked to Improved Clinical Response and Remission in Inflammatory Bowel Disease: A Systematic Review and Pooled Proportion Meta-Analysis. J Clin Med 10:959. doi:10.3390/jcm10050959.

7. Rossen NG, Fuentes S, Van Der Spek MJ, Tijssen JG, Hartman JHA, Duflou A, Löwenberg M, Van Den Brink GR, Mathus-Vliegen EMH, De Vos WM, Zoetendal EG, D'Haens GR, Ponsioen CY. 2015. Findings From a Randomized Controlled Trial of Fecal Transplantation for Patients With Ulcerative Colitis. Gastroenterology 149:110-118.

doi:10.1053/j.gastro.2015.03.045.

8. Moayyedi P, Surette MG, Kim PT, Libertucci J, Wolfe M, Onischi C, Armstrong D, Marshall JK, Kassam Z, Reinisch W, Lee CH. 2015. Fecal Microbiota Transplantation Induces Remission in Patients With Active Ulcerative Colitis in a Randomized Controlled Trial. Gastroenterology 149:102-109. doi:10.1053/j.gastro.2015.04.001.

9. Paramsothy S, Kamm MA, Kaakoush NO, Walsh AJ, van den Bogaerde J, Samuel D, Leong RWL, Connor S, Ng W, Paramsothy R, Xuan W, Lin E, Mitchell HM, Borody TJ. 2017. Multidonor intensive faecal microbiota transplantation for active ulcerative colitis: A randomised placebo-controlled trial. The Lancet 389:1218-1228. doi:10.1016/S0140-6736(17)30182-4.

10. Costello SP, Hughes PA, Waters O, Bryant RV, Vincent AD, Blatchford P, Katsikeros R, Makanyanga J, Campaniello MA, Mavrangelos C, Rosewarne CP, Bickley C, Peters C, Schoeman MN, Conlon MA, Roberts-Thomson IC, Andrews JM. 2019. Effect of Fecal Microbiota Transplantation on 8-Week Remission in Patients With Ulcerative Colitis: A Randomized Clinical Trial. JAMA 321:156-164. doi:10.1001/jama.2018.20046.

11. Ni J, Wu GD, Albenberg L, Tomov VT. 2017. Gut microbiota and IBD: Causation or correlation? Nat Rev Gastroenterol Hepatol 14:573-584. doi:10.1038/nrgastro.2017.88.

12. Khan I, Ullah N, Zha L, Bai Y, Khan A, Zhao T, Che T, Zhang C. 2019. Alteration of Gut Microbiota in Inflammatory Bowel Disease (IBD): Cause or Consequence? IBD Treatment Targeting the Gut Microbiome. Pathogens 8:126. doi:10.3390/pathogens8030126.

13. Ishikawa D, Sasaki T, Osada T, Kuwahara-Arai K, Haga K, Shibuya T, Hiramatsu K, Watanabe S. 2017. Changes in Intestinal Microbiota Following Combination Therapy with Fecal Microbial Transplantation and Antibiotics for Ulcerative Colitis. Inflamm Bowel Dis 23:116-125. doi:10.1097/MIB.0000000000000975.

14. Kump P, Wurm P, Gröchenig HP, Wenzl H, Petritsch W, Halwachs B, Wagner M, Stadlbauer V, Eherer A, Hoffmann KM, Deutschmann A, Reicht G, Reiter L, Slawitsch P, Gorkiewicz G, Högenauer C. 2018. The taxonomic composition of the donor intestinal microbiota is a major factor influencing the efficacy of faecal microbiota transplantation in therapy refractory ulcerative colitis. Aliment Pharmacol Ther 47:67-77. doi:10.1111/apt.14387.

15. Kao D, Roach B, Silva M, Beck P, Rioux K, Kaplan GG, Chang HJ, Coward S, Goodman KJ, Xu H, Madsen K, Mason A, Wong GKS, Jovel J, Patterson J, Louie T. 2017. Effect of oral 
medRxiv preprint doi: https://doi.org/10.1101/2021.08.07.21261556; this version posted August 10, 2021. The copyright holder for this preprint (which was not certified by peer review) is the author/funder, who has granted medRxiv a license to display the preprint in perpetuity. It is made available under a CC-BY 4.0 International license.

capsule vs colonoscopy-delivered fecal microbiota transplantation on recurrent Clostridium difficile infection: A randomized clinical trial. JAMA - J Am Med Assoc 318:1985-1993. doi:10.1001/jama.2017.17077.

16. Adler E, Tabaa A, Kassam Z, Zydek M, Terdiman J, El-Nachef N. 2019. CapsuleDelivered Fecal Microbiota Transplant Is Safe and Well Tolerated in Patients with Ulcerative Colitis. Dig Dis Sci 64:2452-2454. doi:10.1007/s10620-019-05596-5.

17. Crothers, Jessica Wood, TODO. 2020. Daily, Oral FMT for Long-Term Maintenance Therapy in Ulcerative Colitis: Results of a Single-Center, Prospective, Randomized Pilot Study. doi:10.21203/rs.3.rs-62372/v1.

18. Cold F, Browne PD, Günther S, Halkjaer SI, Petersen AM, Al-Gibouri Z, Hansen LH, Christensen AH. 2019. Multidonor FMT capsules improve symptoms and decrease fecal calprotectin in ulcerative colitis patients while treated an open-label pilot study. Scand J Gastroenterol 54:289-296. doi:10.1080/00365521.2019.1585939.

19. Borody TJ, Clancy A. 2019. Fecal microbiota transplantation for ulcerative colitiswhere to from here? Transl Gastroenterol Hepatol 4 doi:10.21037/tgh.2019.06.04.

20. Bibbò S, Settanni CR, Porcari S, Bocchino E, laniro G, Cammarota G, Gasbarrini A. 2020. Fecal Microbiota Transplantation: Screening and Selection to Choose the Optimal Donor. J Clin Med 9 doi:10.3390/jcm9061757.

21. Singh A, Mahajan R, Kao D, Midha V, Sood A. 2020. Long term management of ulcerative colitis with Faecal Microbiota Transplantation. Medicine in Microecology 6:100026. doi:10.1016/j.medmic.2020.100026.

22. Smillie CS, Sauk J, Gevers D, Friedman J, Sung J, Youngster I, Hohmann EL, Staley C, Khoruts A, Sadowsky MJ, Allegretti JR, Smith MB, Xavier RJ, Alm EJ. 2018. Strain Tracking Reveals the Determinants of Bacterial Engraftment in the Human Gut Following Fecal Microbiota Transplantation. Cell Host Microbe 23:229-240.e5. doi:10.1016/j.chom.2018.01.003.

23. Chu ND, Crothers JW, Nguyen LTT, Kearney SM, Smith MB, Kassam Z, Collins C, Xavier R, Moses PL, Alm EJ. 2019. Dynamic colonization of microbes and their functions after fecal microbiota transplantation for inflammatory bowel disease. bioRxiv doi:10.1101/649384.

24. Johnson JS, Spakowicz DJ, Hong B-Y, Petersen LM, Demkowicz P, Chen L, Leopold SR, Hanson BM, Agresta HO, Gerstein M, Sodergren E, Weinstock GM. 2019. Evaluation of $16 \mathrm{~S}$ rRNA gene sequencing for species and strain-level microbiome analysis. Nat Commun 10:5029. doi:10.1038/s41467-019-13036-1.

25. Paramsothy S, Nielsen S, Kamm MA, Deshpande NP, Faith JJ, Clemente JC, Paramsothy R, Walsh AJ, van den Bogaerde J, Samuel D, Leong RWL, Connor S, Ng W, Lin E, Borody TJ, Wilkins MR, Colombel J-F, Mitchell HM, Kaakoush NO. 2019. Specific Bacteria and Metabolites Associated With Response to Fecal Microbiota Transplantation in Patients With Ulcerative Colitis. Gastroenterology 156:1440-1454.e2. doi:10.1053/j.gastro.2018.12.001.

26. Labbé A, Ganopolsky JG, Martoni CJ, Prakash S, Jones ML. 2014. Bacterial Bile Metabolising Gene Abundance in Crohn's, Ulcerative Colitis and Type 2 Diabetes Metagenomes. PLOS ONE 9:e115175. doi:10.1371/journal.pone.0115175. 
medRxiv preprint doi: https://doi.org/10.1101/2021.08.07.21261556; this version posted August 10, 2021. The copyright holder for this preprint (which was not certified by peer review) is the author/funder, who has granted medRxiv a license to display the preprint in perpetuity. It is made available under a CC-BY 4.0 International license .

27. Tiratterra E, Franco P, Porru E, Katsanos KH, Christodoulou DK, Roda G. 2018. Role of bile acids in inflammatory bowel disease. Ann Gastroenterol 31:266-272. doi:10.20524/aog.2018.0239.

28. Heinken A, Ravcheev DA, Baldini F, Heirendt L, Fleming RMT, Thiele I. 2019. Systematic assessment of secondary bile acid metabolism in gut microbes reveals distinct metabolic capabilities in inflammatory bowel disease. Microbiome 7:75. doi: 10.1186/s40168019-0689-3.

29. Vaughn BP, Kaiser T, Staley C, Hamilton MJ, Reich J, Graiziger C, Singroy S, Kabage AJ, Sadowsky MJ, Khoruts A. 2019. A pilot study of fecal bile acid and microbiota profiles in inflammatory bowel disease and primary sclerosing cholangitis. Clin Exp Gastroenterol 12:9-19. doi:10.2147/CEG.S186097.

30. Lavelle A, Sokol H. 2020. Gut microbiota-derived metabolites as key actors in inflammatory bowel disease. Nat Rev Gastroenterol Hepatol 17:223-237. doi:10.1038/s41575019-0258-z.

31. Sinha SR, Haileselassie Y, Nguyen LP, Tropini C, Wang M, Becker LS, Sim D, Jarr K, Spear ET, Singh G, Namkoong H, Bittinger K, Fischbach MA, Sonnenburg JL, Habtezion A. 2020. Dysbiosis-Induced Secondary Bile Acid Deficiency Promotes Intestinal Inflammation. Cell Host \& Microbe 27:659-670.e5. doi:10.1016/j.chom.2020.01.021.

32. Sun R, Xu C, Feng B, Gao X, Liu Z. 2021. Critical roles of bile acids in regulating intestinal mucosal immune responses. Therap Adv Gastroenterol 14:17562848211018098. doi:10.1177/17562848211018098.

33. Fiorucci S, Carino A, Baldoni M, Santucci L, Costanzi E, Graziosi L, Distrutti E, Biagioli M. 2021. Bile Acid Signaling in Inflammatory Bowel Diseases. Dig Dis Sci 66:674-693. doi:10.1007/s10620-020-06715-3.

34. Yang Z-H, Liu F, Zhu X-R, Suo F-Y, Jia Z, Yao S-K. 2021. Altered profiles of fecal bile acids correlate with gut microbiota and inflammatory responses in patients with ulcerative colitis. World J Gastroenterol 27:3609-3629. doi:10.3748/wjg.v27.i24.3609.

35. Schroeder KW, Tremaine WJ, Ilstrup DM. 1987. Coated Oral 5-Aminosalicylic Acid Therapy for Mildly to Moderately Active Ulcerative Colitis. N Engl J Med 317:1625-1629. doi:10.1056/NEJM198712243172603.

36. Shi ZJ, Dimitrov B, Zhao C, Nayfach S, Pollard KS. 2020. Ultra-rapid metagenotyping of the human gut microbiome. bioRxiv 2020.06.12.149336. doi:10.1101/2020.06.12.149336.

37. Parks DH, Chuvochina M, Waite DW, Rinke C, Skarshewski A, Chaumeil P-A, Hugenholtz P. 2018. A standardized bacterial taxonomy based on genome phylogeny substantially revises the tree of life. Nat Biotechnol 36:996-1004. doi:10.1038/nbt.4229.

38. Parks DH, Chuvochina M, Chaumeil P-A, Rinke C, Mussig AJ, Hugenholtz P. 2020. A complete domain-to-species taxonomy for Bacteria and Archaea. Nat Biotechnol 38:1079-1086. doi:10.1038/s41587-020-0501-8.

39. Earley H, Lennon G, Balfe Á, Coffey JC, Winter DC, O'Connell PR. 2019. The abundance of Akkermansia muciniphila and its relationship with sulphated colonic mucins in health and ulcerative colitis. Sci Rep 9:15683. doi:10.1038/s41598-019-51878-3. 
medRxiv preprint doi: https://doi.org/10.1101/2021.08.07.21261556; this version posted August 10, 2021. The copyright holder for this preprint (which was not certified by peer review) is the author/funder, who has granted medRxiv a license to display the preprint in perpetuity. It is made available under a CC-BY 4.0 International license.

40. Bian X, Wu W, Yang L, Lv L, Wang Q, Li Y, Ye J, Fang D, Wu J, Jiang X, Shi D, Li L. 2019. Administration of Akkermansia muciniphila Ameliorates Dextran Sulfate Sodium-Induced Ulcerative Colitis in Mice. Front Microbiol 0 doi:10.3389/fmicb.2019.02259.

41. Vital M, Rud T, Rath S, Pieper DH, Schlüter D. 2019. Diversity of Bacteria Exhibiting Bile Acid-inducible $7 \alpha$-dehydroxylation Genes in the Human Gut. Comput Struct Biotechnol J 17:1016-1019. doi:10.1016/j.csbj.2019.07.012.

42. Song Z, Cai Y, Lao X, Wang X, Lin X, Cui Y, Kalavagunta PK, Liao J, Jin L, Shang J, Li J. 2019. Taxonomic profiling and populational patterns of bacterial bile salt hydrolase (BSH) genes based on worldwide human gut microbiome. Microbiome 7:9. doi:10.1186/s40168-0190628-3.

43. Rao K, Young VB, Malani PN. 2017. Capsules for Fecal Microbiota Transplantation in Recurrent Clostridium difficile Infection: The New Way Forward or a Tough Pill to Swallow? JAMA 318:1979-1980. doi:10.1001/jama.2017.17969.

44. Wilson BC, Vatanen T, Cutfield WS, O'Sullivan JM. 2019. The Super-Donor Phenomenon in Fecal Microbiota Transplantation. Front Cell Infect Microbiol 9 doi:10.3389/fcimb.2019.00002.

45. Anyansi C, Straub TJ, Manson AL, Earl AM, Abeel T. 2020. Computational Methods for Strain-Level Microbial Detection in Colony and Metagenome Sequencing Data. Front Microbiol 11 doi: $10.3389 /$ fmicb.2020.01925.

46. Albanese D, Donati C. 2017. Strain profiling and epidemiology of bacterial species from metagenomic sequencing. Nat Commun 8:2260. doi:10.1038/s41467-017-02209-5.

47. Truong DT, Tett A, Pasolli E, Huttenhower C, Segata N. 2017. Microbial strain-level population structure and genetic diversity from metagenomes. Genome Res 27:626-638. doi:10.1101/gr.216242.116.

48. Podlesny D, Fricke WF. 2020. Microbial Strain Engraftment, Persistence and Replacement after Fecal Microbiota Transplantation. medRxiv 2020.09.29.20203638. doi:10.1101/2020.09.29.20203638.

49. Allegretti JR, Mullish B, Kassam Z, Carrellas M, Marchesi J, Smith M, Geradin Y, Timberlake S, Pratt D, Korzenik J. 2018. Bile Acid Profiles are Not Altered by Fecal Microbiota Transplantation for the Treatment of Primary Sclerosing Cholangitis: Category Award (Liver): Presidential Poster Award: 1017. Off J Am Coll Gastroenterol ACG 113:S574.

https://journals./ww.com/ajg/Fulltext/2018/10001/Bile_Acid_Profiles_are_Not_Altered_by_Fecal. 1017.aspx.

50. Kassam Z, Dubois N, Ramakrishna B, Ling K, Qazi T, Smith M, Kelly CR, Fischer M, Allegretti JR, Budree S, Panchal P, Kelly CP, Osman M. 2019. Donor Screening for Fecal Microbiota Transplantation. N Engl J Med 2.

51. Gilat T, Suissa A, Leichtman G, Delpre G, Pavlotzky M, Grossman A, Fireman Z. 1987. A comparative study of metronidazole and sulfasalazine in active, not severe, ulcerative colitis. An Israeli multicenter trial. J Clin Gastroenterol 9:415-417. doi:10.1097/00004836-19870800000011. 
medRxiv preprint doi: https://doi.org/10.1101/2021.08.07.21261556; this version posted August 10, 2021. The copyright holder for this preprint (which was not certified by peer review) is the author/funder, who has granted medRxiv a license to display the preprint in perpetuity. It is made available under a CC-BY 4.0 International license.

52. Chapman RW, Selby WS, Jewell DP. 1986. Controlled trial of intravenous metronidazole as an adjunct to corticosteroids in severe ulcerative colitis. Gut 27:1210-1212. https://www.ncbi.n/m.nih.gov/pmc/articles/PMC1433885/.

53. Mantzaris GJ, Archavlis E, Christoforidis P, Kourtessas D, Amberiadis P, Florakis N, Petraki K, Spiliadi C, Triantafyllou G. 1997. A prospective randomized controlled trial of oral ciprofloxacin in acute ulcerative colitis. Am J Gastroenterol 92:454-456.

54. Mantzaris GJ, Petraki K, Archavlis E, Amberiadis P, Kourtessas D, Christidou A, Triantafyllou G. 2001. A prospective randomized controlled trial of intravenous ciprofloxacin as an adjunct to corticosteroids in acute, severe ulcerative colitis. Scand J Gastroenterol 36:971974. doi:10.1080/003655201750305503.

55. Köster J, Rahmann S. 2012. Snakemakea scalable bioinformatics workflow engine. Bioinformatics 28:2520-2522. doi:10.1093/bioinformatics/bts480.

56. Merkel D. 2014. Docker: Lightweight Linux containers for consistent development and deployment. Linux J 2014:2:2.

57. 2020. Anaconda Software Distribution. Anaconda Inc. https://docs.anaconda.com/.

58. Kluyver T, Ragan-Kelley B, Pérez F, Granger B, Bussonnier M, Frederic J, Kelley K, Hamrick J, Grout J, Corlay S, Ivanov P, Avila D, Abdalla S, Willing C, team J development. 2016. Jupyter Notebooks a publishing format for reproducible computational workflows, p. 8790. In Loizides, F, Scmidt, B (eds.), Positioning and Power in Academic Publishing: Players, Agents and Agendas. IOS Press doi:10.3233/978-1-61499-649-1-87.

59. Almeida A, Nayfach S, Boland M, Strozzi F, Beracochea M, Shi ZJ, Pollard KS, Sakharova E, Parks DH, Hugenholtz P, Segata N, Kyrpides NC, Finn RD. 2021. A unified catalog of 204,938 reference genomes from the human gut microbiome. Nat Biotechnol 39:105114. doi:10.1038/s41587-020-0603-3.

60. Pedregosa F, Varoquaux G, Gramfort A, Michel V, Thirion B, Grisel O, Blondel M, Prettenhofer P, Weiss R, Dubourg V, Vanderplas J, Passos A, Cournapeau D, Brucher M, Perrot M, Duchesnay É. 2011. Scikit-learn: Machine learning in Python. J Mach Learn Res 12:2825-2830. http://www.jm/r.org/papers/v12/pedregosa11a.html.

61. Højsgaard S, Halekoh U, Yan J. 2005. The R Package geepack for Generalized Estimating Equations. J Stat Softw 15:1-11. doi:10.18637/jss.v015.i02.

62. Guillot G, Rousset F. 2013. Dismantling the Mantel tests. Methods Ecol Evol 4:336-344. doi:10.1111/2041-210x.12018.

63. Lloyd-Price J, Arze C, Ananthakrishnan AN, Schirmer M, Avila-Pacheco J, Poon TW, Andrews E, Ajami NJ, Bonham KS, Brislawn CJ, Casero D, Courtney H, Gonzalez A, Graeber TG, Hall AB, Lake K, Landers CJ, Mallick H, Plichta DR, Prasad M, Rahnavard G, Sauk J, Shungin D, Vázquez-Baeza Y, White RA, Braun J, Denson LA, Jansson JK, Knight R, Kugathasan S, McGovern DPB, Petrosino JF, Stappenbeck TS, Winter HS, Clish CB, Franzosa EA, Vlamakis H, Xavier RJ, Huttenhower C. 2019. Multi-omics of the gut microbial ecosystem in inflammatory bowel diseases. Nature 569:655-662. doi:10.1038/s41586-019-1237-9.

64. Piceno YM, Lin D, LaMere BJ, Zydek M, Chin A, McCauley K, Fadrosh D, Lynch K, Durack J, Umetsu SE, Kassam Z, Terdiman J, Ma A, Somsouk M, El-Nachef N, Lynch SV. 2020. Reduced Mucosal Inflammation and Select Alterations in the Viable Mucosa-Associated 
medRxiv preprint doi: https://doi.org/10.1101/2021.08.07.21261556; this version posted August 10, 2021. The copyright holder for this preprint (which was not certified by peer review) is the author/funder, who has granted medRxiv a license to display the preprint in perpetuity. It is made available under a CC-BY 4.0 International license .

Microbiota Observed in Clinically-Responsive Ulcerative Colitis Patients Following A Single Fecal Microbiota Transplantation in a Pilot Study Evaluating Safety and Efficacy. J Clin Nutr Food Sci 3:27.

65. Caporaso JG, Kuczynski J, Stombaugh J, Bittinger K, Bushman FD, Costello EK, Fierer N, Peña AG, Goodrich JK, Gordon JI, Huttley G a, Kelley ST, Knights D, Koenig JE, Ley RE, Lozupone C a, McDonald D, Muegge BD, Pirrung M, Reeder J, Sevinsky JR, Turnbaugh PJ, Walters W a, Widmann J, Yatsunenko T, Zaneveld J, Knight R. 2010. QIIME allows analysis of high-throughput community sequencing data. Nat Methods 7:335-336. doi:10.1038/nmeth.f.303.

66. Callahan BJ, Mcmurdie PJ, Rosen MJ, Han AW, Johnson AJ, Holmes SP. 2015. DADA2 : High resolution sample inference from amplicon data. bioRxiv 13:0-14. doi:10.1101/024034.

67. Quast C, Pruesse E, Yilmaz P, Gerken J, Schweer T, Yarza P, Peplies J, Glöckner FO. 2013. The SILVA ribosomal RNA gene database project: Improved data processing and webbased tools. Nucleic Acids Res 41:D590-D596. doi:10.1093/nar/gks1219.

68. Yilmaz P, Parfrey LW, Yarza P, Gerken J, Pruesse E, Quast C, Schweer T, Peplies J, Ludwig W, Glöckner FO. 2014. The SILVA and "all-species Living Tree Project (LTP)" taxonomic frameworks. Nucleic Acids Res 42:643-648. doi:10.1093/nar/gkt1209.

69. Davis NM, Proctor DM, Holmes SP, Relman DA, Callahan BJ. 2018. Simple statistical identification and removal of contaminant sequences in marker-gene and metagenomics data. Microbiome 6:226. doi:10.1186/s40168-018-0605-2.

70. Schliep KP. 2011. Phangorn: Phylogenetic analysis in R. Bioinformatics 27:592-593. doi:10.1093/bioinformatics/btq706.

71. Schliep K, Potts AA, Morrison DA, Grimm GW. 2016. Intertwining phylogenetic trees and networks. preprint, PeerJ Preprints doi:10.7287/peerj.preprints.2054v1.

72. Bodenhofer U, Bonatesta E, Horejš-Kainrath C, Hochreiter S. 2015. Msa: An R package for multiple sequence alignment. Bioinformatics 31:3997-3999.

doi:10.1093/bioinformatics/btv494.

73. Wright E S. 2016. Using DECIPHER v2.0 to Analyze Big Biological Sequence Data in R. The R Journal 8:352. doi:10.32614/RJ-2016-025.

74. Xu H, Luo X, Qian J, Pang X, Song J, Qian G, Chen J, Chen S. 2012. FastUniq: A fast de novo duplicates removal tool for paired short reads. PLoS ONE 7:1-6.

doi:10.1371/journal.pone.0052249.

75. Buffalo V. 2018. Scythe - A Bayesian adapter trimmer

https://github.com/vsbuffalo/scythe.

76. Joshi NA, Fass JN. 2011. Sickle: A sliding-window, adaptive, quality-based trimming tool for FastQ files (Version 1.33) https://github.com/najoshi/sickle.

77. Schneider VA, Graves-Lindsay T, Howe K, Bouk N, Chen H-C, Kitts PA, Murphy TD, Pruitt KD, Thibaud-Nissen F, Albracht D, Fulton RS, Kremitzki M, Magrini V, Markovic C, McGrath S, Steinberg KM, Auger K, Chow W, Collins J, Harden G, Hubbard T, Pelan S, Simpson JT, Threadgold G, Torrance J, Wood JM, Clarke L, Koren S, Boitano M, Peluso P, Li H, Chin C-S, Phillippy AM, Durbin R, Wilson RK, Flicek P, Eichler EE, Church DM. 2017. 
medRxiv preprint doi: https://doi.org/10.1101/2021.08.07.21261556; this version posted August 10, 2021. The copyright holder for this preprint (which was not certified by peer review) is the author/funder, who has granted medRxiv a license to display the preprint in perpetuity. It is made available under a CC-BY 4.0 International license.

Evaluation of GRCh38 and de novo haploid genome assemblies demonstrates the enduring quality of the reference assembly. Genome Res 27:849-864. doi:10.1101/gr.213611.116.

78. Langmead B, Salzberg SL. 2012. Fast gapped-read alignment with Bowtie 2. Nat Methods 9:357-359. doi:10.1038/nmeth.1923.

79. Buchfink B, Xie C, Huson DH. 2014. Fast and sensitive protein alignment using DIAMOND. Nat Methods 12:59-60. doi:10.1038/nmeth.3176.

80. Altschul SF, Gish W, Miller W, Myers EW, Lipman DJ. 1990. Basic local alignment search tool. J Mol Biol 215:403-410. doi:10.1016/S0022-2836(05)80360-2.

81. Huerta-Cepas J, Forslund K, Coelho LP, Szklarczyk D, Jensen LJ, von Mering C, Bork P. 2017. Fast Genome-Wide Functional Annotation through Orthology Assignment by eggNOGMapper. Molecular Biology and Evolution 34:2115-2122. doi:10.1093/molbev/msx148. 